\title{
New perspectives for eye-sparing treatment strategies in pri- mary uveal melanoma
}

\author{
Krzysztof Bilminin, ${ }^{1, \#}$ Kamil J. Synoradzki 2,\#, Anna M. Czarnecka ${ }^{3,4}$, Mateusz J. Spałek, Tamara Kujawska ${ }^{5}$, \\ Małgorzata Solnik ${ }^{6}$, Piotr Merks ${ }^{7}$, Mario Damiano Toro ${ }^{8,9}$, Robert Rejdak ${ }^{10}$ and Michał Fiedorowicz ${ }^{2, *}$
}

1 Department of Health Sciences, Jan Długosz University in Częstochowa, 42-200 Częstochowa, Poland; kbilmin@wp.pl

2 Small Animal Magnetic Resonance Imaging Laboratory, Mossakowski Medical Research Institute, Polish Academy of Sciences, 02-106 Warsaw, Poland; ksynoradzki@imdik.pan.pl (K.J.S.); mfiedorowicz@imdik.pan.pl (M.F.)

3 Department of Experimental Pharmacology, Mossakowski Medical Research Institute, Polish Academy of Sciences, 02-106 Warsaw, Poland; anna.czarnecka@gmail.com

4 Department of Soft Tissue/Bone Sarcoma and Melanoma, Maria Sklodowska-Curie National Research Institute of Oncology, 02-781 Warsaw, Poland; mateusz@spalek.co

5 Institute of Fundamental Technological Research, Polish Academy of Sciences, 02-106 Warsaw, Poland; tkujaw@ippt.pan.pl

6 Department of Medicine, Warsaw Medical University, 02-091 Warsaw, Poland; m.solnik98@gmail.com

7 Department of Pharmacology and Clinical Pharmacology, Faculty of Medicine, Collegium Medicum. Cardinal Stefan Wyszyński University in Warsaw, 01-815 Warsaw, Poland; p.merks@uksw.edu.pl

8 Department of Ophthalmology, Jules Gonin Eye Hospital, FondationAsile des Aveugles, University of Lausanne, Lausanne, Switzerland; m.toro@uksw.edu.pl

9 Department of Ophthalmology, University of Zurich, CH-8091 Zurich, Switzerland

10 Department of General and Pediatric Ophthalmology, Medical University of Lublin, 20-079 Lublin, Poland; robertrejdak@yahoo.com

\# These authors contributed equally

* Correspondence: mfiedorowicz@imdik.pan.pl

\begin{abstract}
Simple Summary: Uveal melanoma is the most common intraocular cancer. Radiotherapy (RT) is the mainstay of therapy for most patients with localized uveal melanoma. Photodynamic therapy is based on the selective destruction of cancer cells or pathological vessels. High-Intensity Focused Ultrasound (HIFU) is a promising technology for the thermal destruction of tumors. Sonodynamic therapy (SDT) induces the reactive oxygen species and kills cancer cells. Electroporation delivers drugs or genetic material from the intercellular space to cells. Iontophoresis is a technique in which using electric current increases the biodistribution of drugs. Iontophoresis increases the concentration of drugs, DNA, and RNA. Theranostics incorporates diagnostic imaging and therapy. Although no theranostic markers have been developed specifically for UM, some of them have already found use in ophthalmology. Novel eye-preserving therapeutic approaches for the localized disease are needed.
\end{abstract}

\footnotetext{
Abstract: Uveal melanoma is the most common intraocular malignancy and arises from melanocytes in the choroid, ciliary body, or iris. Radiotherapy is the mainstay of therapy for most patients with localized uveal melanoma. Another RT technique used in the treatment of uveal melanomas is charged-particle radiotherapy. Photodynamic therapy is based on the selective destruction of cancer cells or pathological vessels. High-Intensity Focused Ultrasound (HIFU) is a promising technology of thermal destruction of solid tumors located deep under the skin. The principle of operation is based on the heating of a tumor. Sonodynamic therapy (SDT) induces the reactive oxygen species and kills cancer cells. Electroporation applied in vivo delivers drugs or genetic material from the intercellular space to cells. Iontophoresis is a technique in which using electric current increases the biodistribution of drugs in the eyeball. Transcorneal iontophoresis has been shown to increase the local concentration of antibacterial and antifungal drugs, steroids, DNA, and RNA molecules. Theranosticsincorporates diagnostic imaging and therapy. Although no theranostic markers have
} 
been developed specifically for uveal melanoma, some NPs have already found use in ophthalmology. UM presents an unmet clinical need. Novel eye-preserving therapeutic approaches for the localized disease are needed.

Keywords: uveal melanoma; HIFU; iontophoresis; electrotherapy; nanoparticles; theranostics.

\section{Introduction}

Uveal melanoma (UM) is the most common intraocular malignancy and arises from melanocytes in the choroid ( $90 \%$, fig, 1$)$, ciliary body $(6 \%)$, or iris $(4 \%)$. UM develop most often in individuals with fair skin, light eye color, ocular or oculodermal melanocytosis, cutaneous or iris or choroidal nevus, and BAP1 or BRCA1 mutation carriers [1]. In UM, the median age at diagnosis is 62 years; congenital or infantile melanoma is rare and is not common in children [2]. It is a disease with a poor prognosis as in metastatic setting expected overall survival is no longer than 12 months. In Europe, UM incidence increases with latitude and ranges from 2/106 in Spain and Italy, 4-6/106 in Central Europe, and > $8 / 106$ in Denmark and Norway. Worldwide UM incidence is 1-9/100 000 [3]. In terms of metastasis-free survival Kaplan-Meier estimates of UM at 3, 5, 10, and 20 years are 2\%, $9 \%, 9 \%$, and $20 \%$ for young patients; $6 \%, 12 \%, 23 \%$, and $34 \%$ for mid-aged adults; but as high as $11 \%, 19 \%, 28 \%$, and $39 \%$ in the elderly [4].

\section{Uveal melanoma}

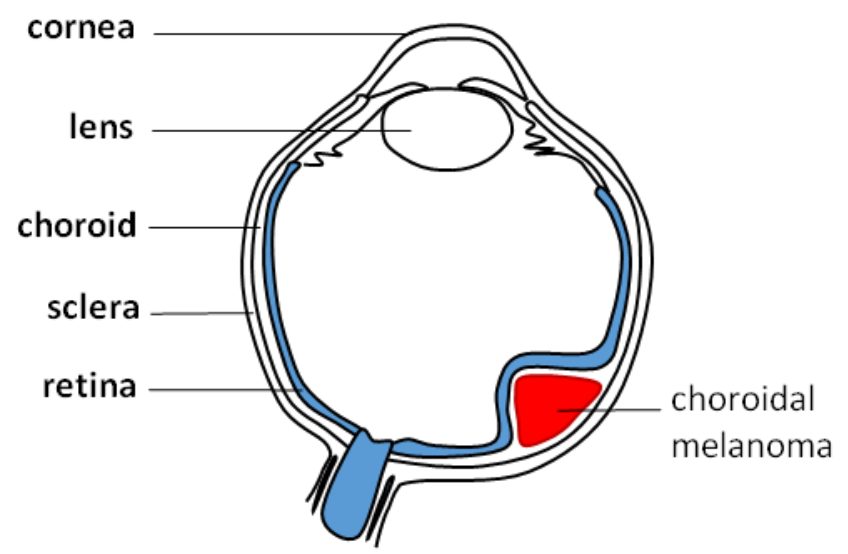

Figure 1. Uveal melanoma and its typical localizations under the choroid.

UM's signs and symptoms are non-specific and include high intraocular pressure,myodesopsia, photopsia, or finally, loss of vision. These tumors are most often detected incidentally in an ophthalmological exam. Besides fair skin type and sunlight ultraviolet (UVA/UVB) exposures, general risk factors of UM development, mutations in the onco-suppressor gene, encoding BRCA1 associated protein 1 (BAP1) have been indicated to increase the risk of UM development. BAP1 mutations also seem significant molecular events in UM and are detected in $47 \%$ of cases [5]. Furthermore, GNAQ and GNA11 gene mutations are often detected in UV, as well as SF3B1 and EIF1AX genes mutations. Moreover, mutations in the promoter of $B R A F, N R A S$, and TERT genes have been described. Among these genes, the presence of TETR, BAP1, SF3B1, and EIF1AX mutations are of prognostic significance [6].

The management of localized UM is either globe-preserving therapy or enucleation. Globe-preserving therapies may be surgical, radiation therapy, or laser therapy. In general, all the treatments are still unsatisfactory in terms of local disease control, as the average treatment failure in all radiation therapies is $6.15 \%, 18.6 \%$ in surgical, and $20.8 \%$ in laser therapies [7]. In particular, radiation therapy modalities include brachytherapy, 
photon-based external-beam radiation, and charged-particle radiation. For brachytherapy reported local recurrence rates are $14.7 \%$ - for ${ }^{106} \mathrm{Ru}$ treatment, $7 \%-10 \%$ for ${ }^{125} \mathrm{I}$, and $3.3 \%$ for ${ }^{103} \mathrm{Pd}$. Brachytherapy does not lead to increased survival rates as compared to enucleation [3].

On the other hand, photodynamic laser photocoagulation and transpupillary thermal therapy (TTT) are treatment modalities that directly focus energy to destroy tumor vascular and reduce local recurrences by injecting and activating light-sensitive compounds and free radicals. TTT has been effective in $80 \%$ of cases of small or indeterminate lesions with few risk factors. Finally, no adjuvant (chemo) therapy has been shown to prolong survival to date [3].

The study aimed to review current and prospective approaches in eye-preserving treating localized ocular melanoma.

\section{Ocular pharmacology}

Ocular pharmacology is extremely unique. The drug administration routes and therapeutic challenges vary depending on the eye segment [8]. The anterior segment of the eye includes the cornea, iris, ciliary body, and lens. Topical application (e.g., drops) is the most common form of pharmacotherapy in this segment. Since the volume of an eye drop $(50 \mu \mathrm{L})$ significantly exceeds the normal tear volume $(7 \mu \mathrm{L})$, most drugs get drained by the nasolacrimal duct or spill over the eyelids.

Moreover, irritant drugs may induce lacrimation causing drug loss. Other factors affecting topical drug residence time include tear film turnover and low corneal permeability $[8,9]$. This results in low bioavailability $(<5 \%)$ of topically applicated treatment [10]. Additionally, self-administration of drops requires great patient compliance, which impacts the therapeutic efficacy. To improve drug contact time and result efficiency in drug delivery, various strategies have been utilized. That includes the development of mucoadhesive polymeric gels, ointments, liposome formulations to increase the carrier's viscosity, and the introduction of sustained and controlled-release therapeutics, such as hydrogel lenses or collagen shields, or drug-cyclodextrin complexes, which increase the aqueous solubility of drugs $[9,11,12]$.

The tissues of the posterior segment of the eye (vitreous humor, retina, choroid, optic nerve, sclera) are mostly reached by systemic and intraocular drug administration [9]. However, oral or intravenous routes are heavily impaired due to the presence of ocular blood barriers. The blood-aqueous barrier (BAB) consists of the non-pigmented epithelium of the ciliary body, the endothelial cells in the iris vessels, the posterior iridial epithelium, and Schlemm's canal's endothelium. On the other hand, the blood-retinal barrier (BRB) is formed by the retinal pigment epithelial cell layer and retinal vascular endothelium $[13,14]$. Both are responsible for maintaining intraocular homeostasis and restricting the passage of blood elements and macromolecules into eye chambers $[9,13]$. Consequently, limited drug influx into the retina and vitreous body requires administering high doses of systemic drugs, which causes various unwanted side effects [11]. With recent developments in nanomedicine, the use of nanoparticles in systemic drug delivery may overcome ocular physiological barriers since they have shown the ability to pass through capillaries and reach the desired site with high selectivity via specific targeting systems [13].

Hence, intravitreal injections remain the most straightforward method in drug administration to the posterior eye segment. However, they mostly require repeated injections resulting in potential side effects including retinal detachment, intraocular hemorrhage, infection, and endophthalmitis [9,15]. Additionally, the procedure is unpleasant for the patient and must be performed by an ophthalmologist, which requires monthly or bimonthly visits [8]. Intravitreal sustained-release devices have been introduced to address the issue (e.g., Vitrasert ganciclovir implant for cytomegalovirus retinitis treatment). The devices are administrated through intraocular surgery; they require periodic replacements, and potential complications are interchangeable with intravitreal injections [11]. 


\section{Radiotherapy}

Radiotherapy (RT) is the mainstay of therapy for most patients with localized uveal melanoma. Due to the predicted radioresistance of melanoma cells, high fraction doses are required to achieve satisfactory response and local control [16]. Thus, the preferred RT methods comprise plaque brachytherapy (BT), charged-particle RT (CRT), and photonbased stereotactic RT (SBRT) [17,18]. Importantly, the occurrence of local relapse of uveal melanoma is related to a risk of distant metastases $[19,20]$. In a systematic review of 49 studies on local therapies for uveal melanoma, the authors reported the local treatment failure rate from $0 \%$ to $55.6 \%$, with follow-up ranging from 10 to 150 months [21]. The weighted average of local failure in all RTs was $6.15 \%$ compared with $18.6 \%$ in eye-sparing surgeries and $20.8 \%$ in laser therapies. However, local control rates varied even between centers that used similar techniques. Therefore, proper RT modality is crucial and should be based on various factors and institutional experience (fig.2, Table 1).

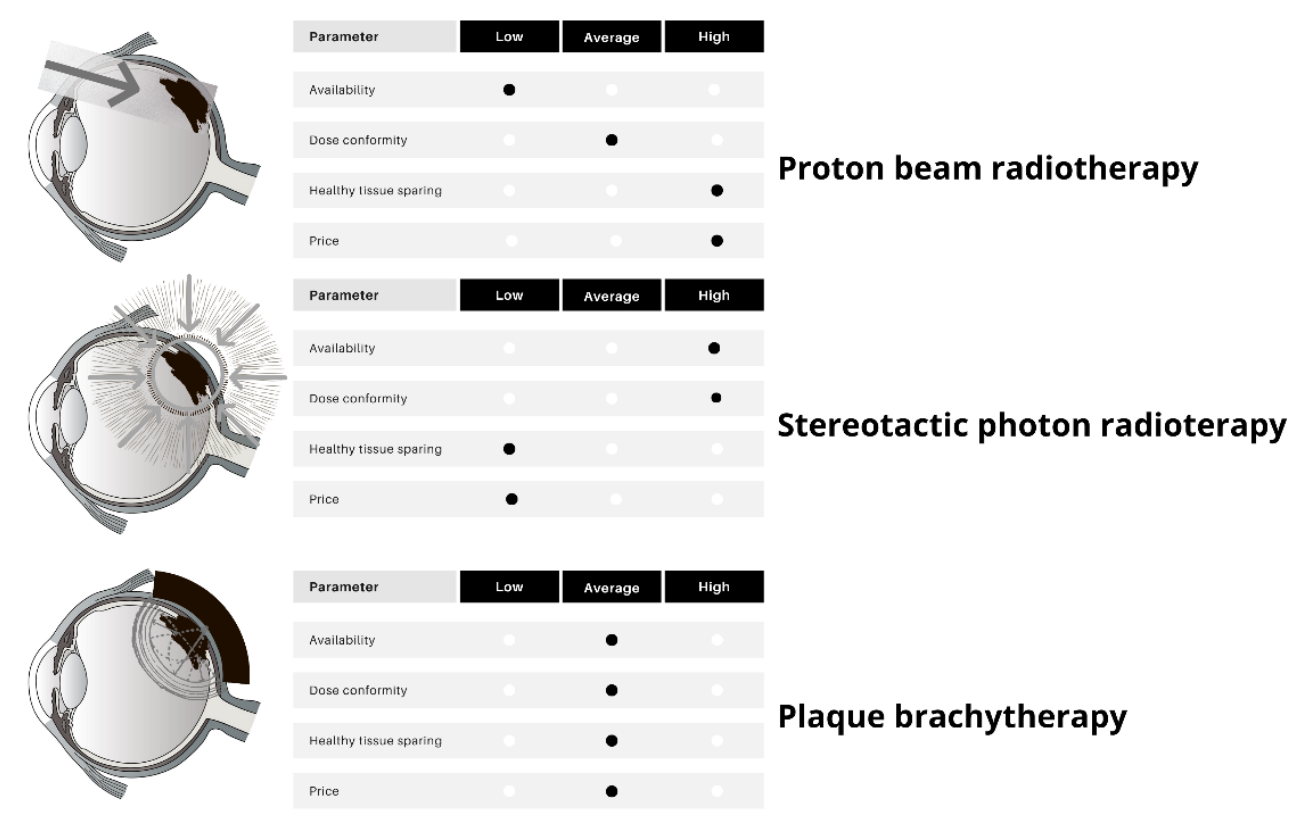

Figure 2. Radiotherapy techniques for uveal melanoma: characteristics, main advantages, and disadvantages. 
Table 1. Selected characteristics of radiotherapy modalities used to treat uveal melanoma.

\begin{tabular}{|c|c|c|c|}
\hline & Brachytherapy & Particle therapy & $\begin{array}{l}\text { Photon stereotactic } \\
\text { body radiotherapy }\end{array}$ \\
\hline Availability & Moderate & Low & High \\
\hline Cost & Moderate & High & Low \\
\hline Tumor size & Small, medium & Medium, large & Medium, large \\
\hline Specific toxicity & $\begin{array}{c}\text { Visual acuity loss, im- } \\
\text { mediate procedural } \\
\text { discomfort }\end{array}$ & $\begin{array}{l}\text { Anterior eye compli- } \\
\text { cations }\end{array}$ & \\
\hline Indications & $\begin{array}{c}\text { Majority of uveal mel- } \\
\text { anomas (also with } \\
\text { limited extrascleral } \\
\text { extension) }\end{array}$ & $\begin{array}{l}\text { Tumors surrounding } \\
\text { the optic disk and fo- } \\
\text { vea; an attempt of } \\
\text { eye-sparing treatment } \\
\text { in large tumors }\end{array}$ & $\begin{array}{l}\text { Rapidly growing tu- } \\
\text { mors }\end{array}$ \\
\hline $\begin{array}{l}\text { Particular contraindi- } \\
\text { cations }\end{array}$ & $\begin{array}{l}\text { Gross orbital exten- } \\
\text { sion, blind painful } \\
\text { eyes, no light percep- } \\
\text { tion }\end{array}$ & None & $\begin{array}{l}\text { Young age predicted } \\
\text { long survival (higher } \\
\text { late complications } \\
\text { rate) }\end{array}$ \\
\hline
\end{tabular}

\subsection{Brachytherapy}

Plaque BT is the most widespread RT method for uveal melanoma available in many specialized RT departments. The main principle is to place radioactive isotopes in the sclera and deliver the prescribed dose to the target volume. It requires ophthalmological surgery due to plaque insertion, suturing, and plaque removal. The irradiation usually lasts between two and four days [22].

Plaque BT replaced enucleation due to favorable results of COMS study published in 2006 that showed the equivalence in the survival of patients with choroidal melanomas randomly allocated to receive iodine- 125 brachytherapy or enucleation [23]. The used isotopes include cobalt-60, iodine-125 (125I), iridium-192, palladium-103, and ruthenium-106 $\left({ }^{106} \mathrm{Ru}\right)$. In clinical practice, the most frequently applied isotopes are ${ }^{106} \mathrm{Ru}$ and ${ }^{125} \mathrm{I}$ due to their wide availability and favorable dose distribution. However, ${ }^{125}$ I is preferred in larger tumors due to its physical properties, namely emission of gamma radiation which penetrates deeper than beta-emitters like ${ }^{106} \mathrm{Ru}$. These observations were confirmed in several studies[24-28]. Intraoperative ultrasonography to verify plaque placement improved the treatment results, especially for tumors localized in the anatomically challenging eye parts, such as its posterior area [29-31].

According to the consensus opinion guidelines published by the American Brachytherapy Society, most melanomas of the iris, ciliary body, and choroid could be treated with BT. Data regarding application technique, dose rate, dosimetry, and quality assurance are presented in detail in the above consensus [32].

\subsection{Stereotactic body radiotherapy}

Photon-based SBRT is also a viable treatment option for uveal melanoma; however, it has been less investigated than BT and CRT. The indisputable advantage of SBRT is the broad accessibility to this technique based on linear accelerators available in the majority of RT departments. The most common fractionation regimen comprises between 50 and 70 Gy given in five consequent fractions. Despite much less extensive experience with 
SBRT for uveal melanoma than for other RT methods, data regarding local efficacy seem to be equivalent. However, SBRT is related to a higher risk of late complications than BT and PT [33].

\subsection{Charged-particle radiotherapy}

Another RT technique used in the treatment of uveal melanomas is CRT. It includes protons, carbon ions, and helium ions [34-37]. Unfortunately, the availability of CRT, especially ion therapy, remains poor due to the high cost of equipment and treatment (Particle Therapy Co-Operative Group). The unique physical properties of CRT beams, namely Bragg peak, allow the deposition of most energy in precisely defined volume with subsequent sharp dose fall-off behind the target volume. CRT provides excellent local control around $90 \%$, similar to this achieved with BT [38]. Nonetheless, due to external beam delivery, there is still a risk of damage to eye structures such as lashes, macula, retina, lens, iris, or cornea.

Interestingly, worse local control after CRT could be associated with several factors: reduced safety margins, presence of large ciliary body tumors, presence of eyelids within the treatment field, wrong positioning of tantalum clips, and male gender [39].

\subsection{Ocular complications of RT}

The risk of ocular complications after RT depends on many factors, including the technique, delivered dose, margins, tumor size, and comorbidities. The ocular complications comprise retinopathy, cataracts, maculopathy, vitreous hemorrhage, retinal detachment, strabismus, secondary glaucoma, optic neuropathy, scleral necrosis, uveitis, and others [40].

Brachytherapy is the most common treatment option for small- and medium-sized UM patients allowing preservation of the eye globe. However, this treatment is associated with possible severe adverse reactions. The most frequent complications include radiation-induced retinopathy $(45 \%-67 \%)$, cataracts $(44 \%)$, neovascular glaucoma $(28 \%)$, and macular edema (25\%). They can result in moderate vision loss in $58 \%$ of patients and poor visual acuity (best corrected worse than $5 / 200$ ) in $28 \%$ within two years [3]. Therefore, the development of safer treatment modalities is needed.

The frequent ocular complication of RT is cataracts. The risk factors include the total dose (especially over $12 \mathrm{~Gy}$ ) and anterior tumors (65-90\% risk of cataract development). The most efficient management is cataract surgery that could be safely performed despite previous irradiation.

Retinopathy may manifest clinically or be asymptomatic. Early diagnosis of radiation-induced retinopathy can be performed using optical coherence tomography. The typical signs are telangiectasia, exudates, cotton wool spots, and microaneurysms. In advanced stages, it could lead to vision loss due to ischemic necrosis. The most important risk factors of radiation-induced retinopathy are diabetes, hypertension, total delivered dose, thick tumors, and proximity of the target volume to the foveola. The available treatment methods include photodynamic therapy, laser photocoagulation, vitrectomy, oral pentoxifylline, hyperbaric oxygen, and intravitreal injection of corticosteroids or antiVEGF agents [41].

Maculopathy and optic nerve neuropathy occur in 25\% and $8 \%-14 \%$ of patients after RT [42,43]. The incidence of these complications severely influences visual acuity [44]. Their development's most important risk factors are tumor location, thickness, volume, and total dose given to the fovea $[45,46]$. Radiation-induced maculopathy may be effectively managed by intravitreal injections of anti-VEGF drugs or dexamethasone [47].

The less frequent but severe complication is secondary glaucoma that is typically refractory to intraocular pressure-reducing agents. It occurs in $2-15 \%$ of patients who underwent eye RT and is the second most frequent reason for enucleation after irradiation $[48,49]$. The risk factors for secondary glaucoma are larger and thicker tumors, more 
advanced age, chronic retinal detachment, and high tumor vascularity [42,48]. The available treatment methods include intravitreal injection of anti-VEGF agents, trans-scleral cyclophotocoagulation, and enucleation [50,51].

In summary, RT is an effective but relatively toxic treatment for uveal melanoma. The proper qualification should include a comprehensive ophthalmologic and oncologic assessment of the risks and benefits of each RT method. The development of equally effective but less toxic eye-sparing treatment strategies is warranted.

\section{Photodynamic therapy}

Photodynamic therapy (PDT) is a commonly used modality in treating various kinds of eye diseases, such as choroidal hemangioma, polypoidal choroidal vasculopathy, central serous chorioretinopathy, non-AMD choroidal neovascularisation, and currently less often in neovascular AMD[52]. Apart from that, PDT is employed to treat eye tumors, including uveal melanoma.

Photodynamic therapy (PDT) action is based on the selective destruction of cancer cells or pathological vessels. The PDT mechanism uses light to activate photosensitizers, generating reactive oxygen species that kill cells [53-55]. This reaction activates immune factors such as histamine, thromboxane, and TNF- $\alpha$ cytokines. Due to its specific mechanism of action, Photodynamic therapy minimizes damage to normal cells [53]. An important factor determining the effectiveness of this method is the selection of the photosensitizer, which should preferentially accumulate in cancer cells and be susceptible to light activation.

Additionally, it should be non-toxic to normal cells. An example of such a compound is Tanshinone IIA, which accumulates in the nucleus of human choroidal melanoma MUM-2B cells and, upon light activation, generates ROS and induces apoptosis [56]. Another group of compounds commonly used in PDT is porphyrins and their derivatives. Studies carried out by Leviskas B et al. have shown that Metalloporphyrin Pd (T4) is used alone or in combination with 5-aminolevulinic acid (the porphyrin synthesis precursor) is effective in PDT against highly invasive uveal melanoma cell line C918 in vitro [54].

Currently, in clinical settings, a derivative of porphyrin - verteporfin is used as a photosensitizer (tab. 2). Although it is approved for treating AMD and CNV [57], studies have shown that verteporfin mediated PDT is an effective, safe, and well-tolerated method of uveal melanomas treatment [58,59]. In a case series conducted on 15 patients with small pigmented posterior poles, choroidal melanoma response to treatment was confirmed in 12 patients. The main outcomes were reduced subretinal fluid, improved visual acuity in some patients, and decreased tumor thickness [58]. In another study, complete tumor regression was observed in $67 \%(\mathrm{n}=12)$ and improved visual acuity in 1 patient and stable results in the others. PDT therapy, also characterized by a good prognosis, allowing patients to maintain good vision [58,60]. Although numerous advantages were shown in the studies, most patients' observations after PDT were performed for a limited time. Therefore, to confirm the long-term effects of PDT, longer observations are necessary [61,62].

Recent studies carried out by Roelofs K. A. et al. indicate a risk of recurrence following PDT, suggesting that PDT with verteporfin should only be applied in these cases of choroidal melanoma, where other treatment methods that could provide better control over the tumor cannot be implemented. A recently published meta-analysis summarized verteporfin-mediated PDT results in uveal melanoma from 7 studies involving 167 patients [63]. The main outcomes of this metaanalysis were regression of the disease and response to treatment observed in $80 \%$ of patients, with a mean follow-up of 50 months. The authors also stated that further research is needed to determine the inclusion criteria for PDT and assess parameters and long-term effects [64]. Additionally, it is worth considering improving PDT or finding a more effective method with a similar mechanism. Perhaps sonodynamic therapy could be a better therapeutic option. It works similarly to PDT, with the difference that ultrasounds are used to activate the photosensitizer. The 
potential benefits, advantages, and possibilities of using SDT in ocular oncology are part of the publication.

Table 2. Ongoing clinical trials investigating new treatment modalities for localized uveal melanoma. Clinical trials were searched on https://www.clinicaltrials.gov and https://www.clinicaltrialsregister.eu with terms "uveal melanoma" and "uveal melanoma treatment" on 10/15/2021.

\begin{tabular}{|c|c|c|c|}
\hline Investigated treatment & Clinical trial & Country & Phase \\
\hline $\begin{array}{c}\text { Autologous dendritic cells } \\
\text { loaded with autologous tumor } \\
\text { RNA }\end{array}$ & NCT01983748 & Germany & Phase 3 \\
\hline $\begin{array}{l}\text { Selumetinib- methyl ethyl ke- } \\
\text { tone (MEK) inhibitor in patients } \\
\text { with unresectable uveal mela- } \\
\text { noma }\end{array}$ & NCT02768766 & USA & Phase 1 \\
\hline $\begin{array}{l}\text { Pegylated arginine deiminase } \\
\text { (ADI-PEG 20), combined with } \\
\text { immunotherapy drugs } \\
\text { nivolumab and ipilimumab in } \\
\text { patients with unresectable } \\
\text { uveal melanoma }\end{array}$ & NCT03922880 & USA & Phase 1 \\
\hline $\begin{array}{l}\text { Hypofractionatedlinear acceler- } \\
\text { ator radiotherapy }\end{array}$ & NCT00872391 & Austria & Not-applicable \\
\hline $\begin{array}{l}\text { Endoresectionor transpupillary } \\
\text { thermotherapy when en- } \\
\text { doresection is not feasible in pa- } \\
\text { tients with large uveal mela- } \\
\text { noma }\end{array}$ & NCT02874040 & France & Not-applicable \\
\hline $\begin{array}{l}\text { Intravitreal injection of ICON- } \\
1 \text { (human immuno-conjugate } 1 \text { ) }\end{array}$ & NCT02771340 & USA & Phase 1 \\
\hline $\begin{array}{l}\text { Stereotactic radiotherapy fol- } \\
\text { lowed by intravitreal afliber- } \\
\text { cept injection }\end{array}$ & NCT03712904 & USA & Phase 2 \\
\hline $\begin{array}{l}\text { Interferon alfa- } 2 b \text { with dacarba- } \\
\text { zine in patients with proven } \\
\text { monosomy } 3 \text { and/or } 8 q \text { amplifi- } \\
\text { cation }\end{array}$ & NCT01100528 & USA & Phase 2 \\
\hline $\begin{array}{l}\text { Suprachoroidal administra- } \\
\text { tion of AU-011 (human papil- } \\
\text { lomavirus virus-like particles } \\
\text { conjugated with IR700 dye AU- } \\
\text { 011) in patients with small cho- } \\
\text { roidal melanoma }\end{array}$ & NCT04417530 & USA & Phase 2 \\
\hline $\begin{array}{l}\text { Light-activated AU-011 in pa- } \\
\text { tients with small choroidal mel- } \\
\text { anoma }\end{array}$ & NCT03052127 & USA & Phase 1B/2 \\
\hline
\end{tabular}




\begin{tabular}{cccc}
\hline $\begin{array}{c}\text { Ziv-aflibercept (VEGF blocker) } \\
\text { in patients with inoperable } \\
\text { uveal melanoma }\end{array}$ & NCT00450255 & USA & Phase 2 \\
\hline $\begin{array}{c}\text { Autologous dendritic cells } \\
\text { loaded with autologous tumor }\end{array}$ & $2007-007847-28$ & Germany & Phase 3 \\
RNA in patients with proven & & \\
monosomy 3 after surgical re- & & \\
section of uveal melanoma to & & \\
prolong disease-free survival & & \\
\hline
\end{tabular}

\section{High Intensity Focused Ultrasoundablative technology}

In recent years, an innovative therapeutic approach using High-Intensity Focused Ultrasound (HIFU) has been proposed to treat solid tumors located in various organs. The HIFU technique is a promising and dynamically developing technology of thermal destruction of solid tumors located deep under the skin due to its non-invasive nature (without surgical intervention), lack of ionization, the possibility of repeated treatment, minimal pain for the patient, low treatment and operating costs, as well as minimal side effects. In clinical practice, the ablative technique using HIFU has been used recently to treat solid tumors of the prostate [65], liver [66,67], kidney [66], or breast [68-72] cancers, as well as uterine fibroids [73].

The principle of operation of this technique is based on a very quick ( $<3$ seconds) heating of a small local volume inside the treated tumor to a temperature above $56{ }^{\circ} \mathrm{C}$, leading to its coagulation necrosis [74] due to the absorption of the energy of ultrasonic waves concentrated in the focal volume of the beam (fig. 3), as well as due to the cavitation [75] that destroys the tissue mechanically. The critical condition is to raise the temperature very quickly to a cytotoxic level so that the tissue vascular system does not significantly influence the volume of damaged tissue. The extent of the ellipsoidal volume of the necrotic lesion formed by the HIFU beam reflects its focal volume. Its size depends on the geometry and acoustic properties of the HIFU beam used and the acoustic and thermal properties of the tissues through which the ultrasonic waves propagate.

The typical dimensions of the ellipsoidal necrotic lesion, induced in tissue by the HIFU beam and reflecting its focal volume, are as follows: the diameter is in the order of one acoustic wavelength $\lambda$, and the length is in the order of 5-7 $\lambda$ [57]. For example, for a $1 \mathrm{MHz}$ HIFU beam, the wavelength in soft tissues is approximately $1.6 \mathrm{~mm}$. Therefore, the extent of the necrotic lesion created in tissue by such a beam will have approx. $1.6 \mathrm{~mm}$ in diameter and approx. $10 \mathrm{~mm}$ in length. Meanwhile, for a beam with a frequency of 10 $\mathrm{MHz}$, the diameter of the necrotic lesion will be about $0.16 \mathrm{~mm}$, and the length about 1 $\mathrm{mm}$. The microscopic image of necrosis induced by HIFU differs from that caused by ischemia. The margin between completely damaged cells and healthy tissues is not more than $50 \mu \mathrm{m}$ [76]. High precision of the therapy is very important for the patient's safety. 


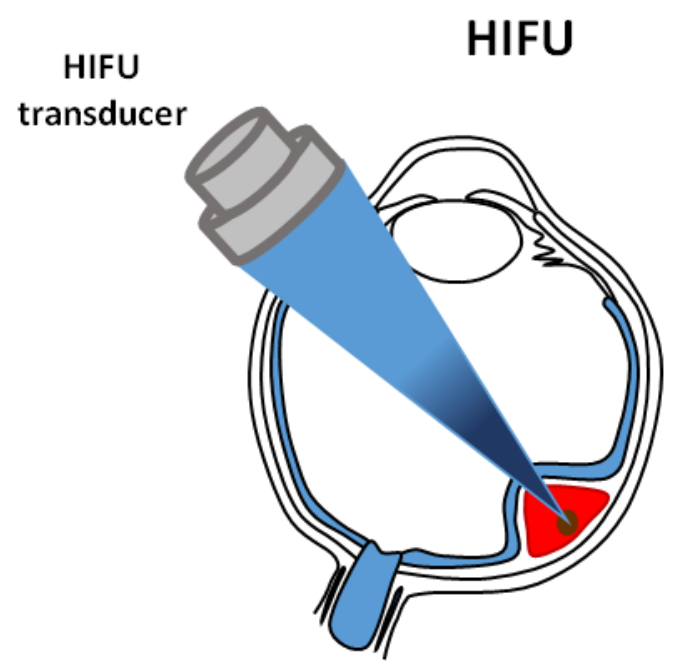

Figure 3. An idea of High Intensity Focused Ultrasoundablative technology. The principle of operation of this technique is based on very quick heating of a small local volume inside the treated tumor, leading to its coagulation necrosis and cavitation.

To cover the entire tumor with necrosis, it is necessary to penetrate its entire volume with the focal volume of the HIFU beam. The entire tumor volume can be ablated by scanning it with a series of single exposures to the HIFU beam moved along a programmed trajectory (with a selected distance and time interval between exposures) using a mechanical precision positioning using an electronic control system [77].

The concentration of energy of ultrasonic waves into a small local volume inside the tumor can be achieved by using both single-element piezoceramic HIFU transducers in the shape of a spherical bowl of large-diameter and by arranging many small piezoceramic transducers on the surface of the spherical bowl. Depending on the excitation mode, the HIFU transducer can generate continuous or pulsed waves. In older generation devices, the tumor is scanned using a HIFU beam generated by a single-element transducer with a fixed focal length, moved in 3D space by a mechanical precision positioning system [78]. Thanks to the development in the field of electronics and the technology of producing multi-element piezoceramic transducers, it has become possible to build the new generation HIFU devices in which the focusing of the beam in 3D space and time, as well as the scanning of the tumor by this beam, is carried out using electronic control of the amplitude and time delay of pulses exciting each element of the transducer separately [77].

Multi-element phased-array HIFU probes provide faster movement of the HIFU beam focus within the tumor and greater possibilities of adjusting its geometric dimensions thanks to the flexibility of electronic control and the ability to create multiple foci at once, the spatial synthesis of which leads to a shorter treatment time. Since the heterogeneity of the tissues through which the pulsed focused ultrasound waves propagate can reduce the focus sharpness, especially in tumors located deep under the skin, various methods of phase correction are used to ensure the safety of the therapy for the patient [77].

The choice of the optimal frequency of the HIFU beam depends on the organ to be treated and is a compromise between the depth of the tumor under the skin and the desired rate of temperature rise. The more shallow the tumor is located under the skin, the higher the HIFU beam frequencies used. For example, to treat tumors located inside the eye (e.g., uveal melanoma), a HIFU beam with a frequency above $10 \mathrm{MHz}$ would be needed $[77,78]$.

HIFU transducers in ablative devices have a large radiation aperture, and the ratio of their diameter to the radius of curvature is smaller or close to 1 . The choice of such transducers is dictated by the beam they generate should have a large opening angle. As a 
result, it penetrates deep into the body by passing through a large skin surface, where its intensity is much lower than at the focus of the HIFU beam. This helps to avoid skin burns [77].

To couple the acoustic impedances of the HIFU transducer and tissue, a matching medium is used, usually, water which is also a cooling medium. Planning the therapy and monitoring and controlling its course may be achieved using two visualization techniques: ultrasound imaging (USI) or magnetic resonance imaging (MRI).

So far, the main clinical application of the HIFU technique in ophthalmology is the treatment of patients with refractory glaucoma. For this purpose, older-generation HIFU devices have been used so far, using single-element HIFU transducers with mechanical positioning of the focus of the HIFU beam inside the treated tissue. Devices such as the Sonocare CST-100 (SonocareInc, Ridgewood, NJ, USA) have been used in clinical practice primarily for the treatment of eyes with refractory glaucoma by thermal damage to the ciliary body (HIFU cyclocoagulation), leading to a significant reduction in intraocular pressure $[79,80]$. However, due to the complexity and duration (approx. 2 hours) of the treatment procedure, as well as the relatively large focal volume of the HIFU beam used, resulting from its too low frequency $(5 \mathrm{MHz})$ and leading to complications caused by damage to adjacent healthy tissues, the use of this device was discontinued. In 2011, to reduce intraocular pressure in patients with refractory glaucoma, Aptel et al. [47] used circular ultrasound cycloagulation using HIFU beams generated by six rectangular concave transducers evenly spaced on the surface of the annular segment of the sphere. Six locations around the circumference, $1 \mathrm{~mm}$ behind the corneal limbus, were subjected to continuous ultrasound waves focused on the ciliary body, causing thermal damage to the body at six locations. For this purpose, a miniaturized HIFU EyeOP1 device was built.

The use of high-intensity focused ultrasound in oncology has been studied for many years. Still, only in the last decade, this technology has reached a level that allows it to be safely used in clinical practice. Existing commercial devices using the HIFU technique are used in clinical practice for thermoablation of tumors of the prostate, breast, liver, kidney, and uterine fibroids.

However, the standards for using the HIFU technique for the ablative treatment of uveal melanoma are much stricter than any other anatomical organ. Such requirements would be met by new-generation miniaturized multi-element phased array HIFU devices. The position and size of the focal volume of the HIFU beam can be electronically controlled, synthesized, and guided to the treated tumor volume using magnetic resonance imaging combined with thermometry or utilizing high-frequency ultrasound imaging.

At the current stage of development, such devices have not yet been created. However, the implementation of miniaturized multi-element high-frequency (>10 MHz) HIFU phased array transducers capable of generating pulsed beams with electronically steered and synthesized focus, targeted on the treated tumor using MR imaging combined with thermometry or high-frequency ultrasound imaging will open up new perspectives for development HIFU techniques in the treatment of various eye diseases including uveal melanoma.

Such a new generation device that will ensure the effectiveness and safety of therapy has a good chance of achieving commercial success. However, early detection and early tumor treatment are critical to long-term survival following HIFU treatment for uveal melanoma.

\section{Sonodynamic therapy}

Sonodynamic therapy (SDT) was developed from photodynamic therapy (PDT) [1]. The similar effect of both therapies is to induce the reactive oxygen species (ROS) and kill cancer cells, but SDT and PDT's excitation mechanisms are different (fig. 4). Moreover, SDT relies on the synergy of ROS production and mechanical pressure. It damages the mitochondrial membrane (and structures on its surface) opposite PDT, where this membrane remains intact. SDT is less invasiveness than PDT - it does not require endoscopic pierced optical fiber or surgical exposure of tumor, guidance by CT or MRI. Ultrasounds 
may penetrate deep into tissues (Figure 3), opposite photodynamic, limiting permeability light to deep tumor tissues $[81,82]$.

Treated lesions are accessible, and this type of therapy is less effective for large tumors treatment. Usage of photosensitizers is associated with the necessity of avoiding sunlight for several weeks by a treated patient. Moreover, SDT kills cancer cells by simultaneously reducing the damage of adjacent normal tissue [83]. SDT gives a better outcome on dark pigmented nidusin melanoma skin cancer than PDT $[84,85]$.

\section{SDT}

\section{Sonosensitizer activation Cancer cells apoptosis}
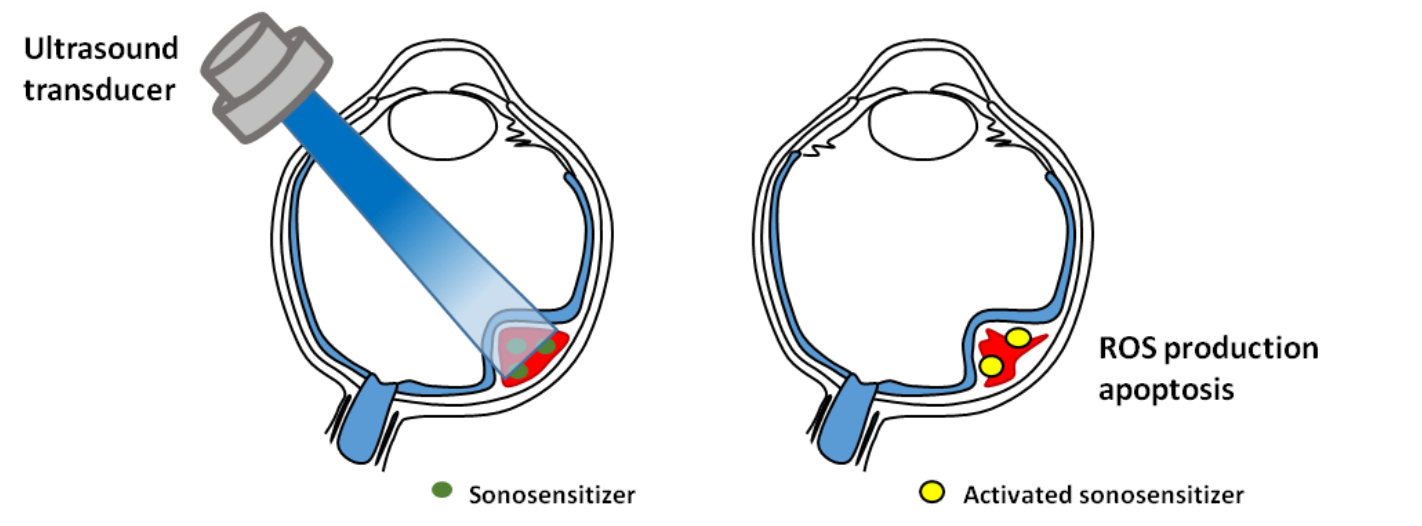

Figure 4. An idea of sonodynamic therapy. This technology was developed from photodynamic therapy. Both of them induce the reactive oxygen species (ROS) and kill cancer cells. The effect is mediated by the photosensitizers.

A detailed mechanism of SDT is still unclear. Sound waves deliver a portion of energy absorbed by the sonosensitizer, and its exciting electrons initiate chemical reactions with biomolecules and water. The products of these reactions are free radicals $1 \mathrm{O} 2$. Consequently, sonodynamic therapy induces cavitation effect, generation of free radicals, and direct apoptosis of cancer cells. Cavitation is acting upon in the liquid, wherein ultrasonic filed microbubbles arise, vibrate, and collapse. Cavitation divide into non-inertial and inertial. Non-inertial occurs in low-intensity ultrasound. Cavitation bubbles oscillate and affect surrounding suspended particles. Inertial cavitation occurs when liquid is subjected to high-intensity ultrasound. Bubbles absorb more energy and release it on a small area, resulting in high temperature, pressure, and generation of free radicals [84]. The biological effect on cells of non-inertial cavitation is limited to changing membrane permeability. Inertial cavitation may destruct the cytoskeleton, cell membrane structures, and enzymes, killing surrounded cells [84]. Tumor treatment requires both types of cavitation (damage tumor cells by protecting the surrounding tissues or destroying tumor cells with some margin). Non-inertial cavitation may turn into inertial [84].

Sonodynamic therapy induces apoptosis. A large quantity of ROS produced during SDT affects reducing mitochondrial membrane potential and drive to apoptosis. SDT also induces expression of Bcl-2 family proteins, increases the amount of BAX/BAX or $\mathrm{BAX} / \mathrm{Bcl}-2$ dimers, and reduces mitochondrial membrane, which leads to apoptosis. STD drives to $\mathrm{Ca}^{2+}$ overload. In vitro studies on glioma cell line (C6) shows that in cells treated by low-level ultrasound in combination with hematoporphyrinmonomethyl ether (HMME) starts ROS production, increase the intercellular concentration of $\mathrm{Ca}^{2+}$ level, decrease mitochondrial membrane potential, and release cytochrome c [86]. HMME-SDT or protoporphyrin IX (PpIX)-mediated sonodynamic therapy (PpIX-SDT) also inducesapoptosisleukemia U937 and K562 cell lines. Changes after sonodynamic treatment on the 
cellular level apply to nuclear morphology (chromatin condensation), translocation of BAX protein (form cytoplasm to mitochondria), and caspase activation $[87,88]$. Apoptosis activation by SDT may occur by also by activating exogenous pathways and up-regulation expression of FAS/FASL receptors [84].

Low-intensity therapeutic ultrasound (5-aminolevulinic acid as a sonosensitizer) in mice transplanted with B16F10 melanomas activate a local immune response. In the tumor microenvironment were observed localization of M1 type macrophage cells, a high level of inflammatory cytokines TNF- $\alpha$ and IFN- $\gamma$, and faster maturation of dendritic cells [89].

Some sonosensitizers derive from photosensitizers, e.g., protoporphyrin derivates [83]. First, SDT was applied to treat mouse sarcoma and rat ascites hepatoma cells by hematoporphyrin in the acoustic field [90]. The group of these compounds consists of hematoporphyrin (Hp), photofrin, hematoporphyrin monomethyl ether (HMME), protoporphyrin IX (PpIX), ATX-70, and their novel derivates. These compounds were tested in cell and animal models in several tumor types (mammary or breast cancer, glioma, osteosarcoma, or leukemia) [83].

A newer group of compounds used in SDT therapy are nano-sensitizers. These compounds possess good solubility and could prolong blood circulation and accumulate tumor lesion sites [91]. It can be divided into intrinsic sonosensitizers (titanium dioxide $\mathrm{TiO}_{2}$, nanoparticles - NPs) and nanoparticle-assisted sonosensitizers. From the first group, the most extensively studied is $\mathrm{TiO}_{2}$. It is low-cost and easy to fabricate, and due to its semiconductor properties, it may generate ROS [92]. In melanoma cell line (C32), irradiation by ultrasound in the presence of $\mathrm{TiO}_{2}$ results in indamages of cell membranes, induction of apoptosis. In the mouse in vivo model, combination SDT with $\mathrm{TiO} 2$ resulted in significant inhibition of tumor growth compared with untreated mice. Histopathological analysis of tumors shows the presence of necrotic cells and neutrophils [93].

Another group of sonosensitizers are xanthenes. Compounds belonging to this grouplike eosin, fluorescein, and rhodamines possess good water solubility [83]. One of them is Rose Bengal which is a fluorescein derivate. It is used to stain the ocular surface epithelium to assess damage in ocular surface diseases [94]. It was tested in melanoma cell lines [95,96]. In A375 cells, after sunlight exposure, it causes a phototoxic effect resulting in DNA damage and apoptosis of tumor cells. It is recommended to prevent natural sunlight exposure after using Rose Bengal [96].

Attempts to apply sonodynamic therapy have been made concerning many types of neoplasms, such as glioblastoma, lung adenocarcinoma, human lung adenocarcinoma, leukemia, melanoma, sarcoma, tongue squamous carcinoma, breast and hepatocellular carcinoma [97]. So far, this form of therapy has not been studied concerning uveal melanoma. SDT seems to be safer and selective than PDT. Ultrasound can be tightly focused with good penetration through soft tissue [98]. There is a possibility of non-invasive ultrasound of the eye (through the front of the eye), but appropriate transducers and then check their effectiveness in in vivo tests must be carried out.

\section{Electrically-enhanced drug delivery}

Electroporation applied in vivo delivers drugs or genetic material from the intercellular space to cells by temporarily permeabilizing cell membranes using a short-term high voltage electrical pulse (fig. 5) [99]. The first stage is the introduction of a substance (drug, DNA) into the intercellular space. This approach can be achieved through intravenous or local administration (e.g., intratumorally, directly into cancerous tissue). Intravenous administration is less effective in tumors because of the usually increased pressure in the intercellular space. An example is intra-articular administration of bleomycin combined with electrotherapy, which was more effective than intravenous administration of this drug [100]. In the case of intraocular administration, an additional limitation is the presence of the blood-retinal, blood-aqueous humor, and blood-vitreous barriers. Electroporation should bring the greatest benefits in the case of administering drugs with low permeability through biological, hydrophobic barriers. The use of several 
chemotherapeutic agents in combination with electrotherapy was investigated, including doxorubicin, daunorubicin, etoposide, paclitaxel, vinblastine, vincristine, cyclophosphamide, carboplatin, cisplatin, bleomycin. Currently used in cancer patients is the administration of bleomycin and cisplatin by electroporation [101].

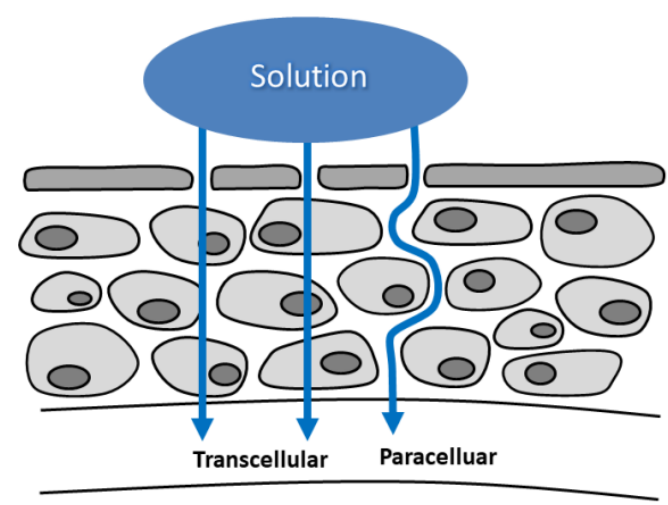

Figure 5. An idea of electrically-enhanced drug delivery. The applied drug may be transported either paracellularly or transcellularly.

In contrast to iontophoresis (described below), in vivo electroporation in ophthalmology has so far been used primarily in gene transfection. The plasmids were administered subconjunctivally to the cornea, and short-term electrical pulses were applied. No side effects were observed with the application of eight electrical pulses with a length of $10 \mathrm{~ms}$ to $200 \mathrm{~V} / \mathrm{cm}$. Obtained results were better than with DNA injections without the application of electrical pulses [102]. The effectiveness and lack of noticeable damage to the eyeball have also been demonstrated in the case of electrotransfer of plasmid DNA administered into the extravascular space in rats [103]. Data from in vitro studies indicate that electroporation-assisted administration of chemotherapeutic agents in ocular neoplasms (e.g., ocular melanoma) may also be a promising new therapy [104].

\section{Iontophoresis}

Iontophoresis is a non-invasive technique in which using low-intensity electric current allows to increase the biodistribution of ionized drug molecules in the tissues of the eyeball, particularly in the cornea and sclera. Transcorneal iontophoresis has been shown to increase the local concentration of antibacterial and antifungal drugs, steroids, DNA, and RNA molecules $[105,106]$. EyeGate company has developed a transscleral iontophoresis device and has completed Phase III clinical trials of EPG- 437 formulation (dexamethasone formulation developed for iontophoresis administration) for anterior uveitis. The treatment results were similar to the standard therapy (prednisolone in the form of eye drops). Still, the risk of increased intraocular pressure and the frequency of drug administration was lowered [107].

Iontophoresis with carboplatin delivery was a promising option for retinoblastoma treatment. Transcorneoscleral delivery of drug results in dose-dependent inhibition of intraocular retinoblastoma. In the mouse model, dose $7,0 \mathrm{mg} / \mathrm{ml}$ was evaluated as tumor control dose for $50 \%$ eyes treated. In this dose, there were no corneal toxicity signs observed [108]. There were no toxicity signs in the rabbit eye (more anatomically similar to the human eye) after six transscleral applications of carboplatin at $14 \mathrm{mg} / \mathrm{ml}$ [109].

The disadvantage of the iontophoresis technique is its low effectiveness to deeper tissues of the eyeball, its limited effectiveness of supporting the internalization of drug molecules into cells, and its limited ability to administer drugs locally precisely. However, there are attempts to deliver nanoparticles to sites near the posterior pole region of the eye. In ex vivo and in vivo animal model iontophoresis using microneedle-based device 
allow delivering charged nanoparticles to the posterior region of the suprachoroidal space (SCS; $>9 \mathrm{~mm}$ from the limbus) with average $6 \mathrm{~nm}$ penetration [110].

In electrochemotherapy (ECT), electric pulses generate and open transient pores in the cell membrane and enable the influx of drug (chemotherapeutic) molecules into the cytosol. Its principal advantage is local dose intensity. The high intratumoral drug concentration is achieved, and cytotoxicity is increased by $\sim 8000$ fold for bleomycin and $\sim 80$ fold for cisplatin [111]. Besides electropermeabilization and electrophoresis, other mechanisms that might also play a role in electroporation are passive diffusion, convection, macropinocytosis, and endocytosis (electroendocytosis) possible uptake-mechanisms for neutral particles during electroporation. Recently, a meta-analysis of ECT clinical trials showed that the overall objective response rate (ORR) ranges from $62.6 \%$ to $82.2 \%$, depending on the drug's type and route of administration, type of cancer, and tumor size. Over the last few years, great efforts have been undertaken to extend ECT to non-cutaneous tumor locations, including the liver, pancreas, bones, and brain. Moreover, an endoscopic electrode was developed to treat colon and rectal cancer [112].

Sensitive tissues with acute toxicity have also been investigated as ECT manageable. In preclinical studies, several centers use needle-like electrodes for localized electroporation in the postnatal brain in rats and mice. Electroporation does not result in behavioral side effects and no motor response or seizure-like activity. Most recently, in vivo single-cell electroporation was used in rats for $\mathrm{Ca}^{2+}$ indicator loading. Successful loading of these tracers into the neurons was also confirmed [113].

The extracellular matrix composition influences electroporation efficiency: soft tumors with larger spherical cells, low proteoglycan, and collagen content, and low cell density are more effectively transfected [114]; therefore, uveal melanoma seems like a good potential candidate for that type of treatment.

ECT was evaluated in in vitro (spheroid) and in vivo (chick embryo chorioallantoic membrane (CAM)) models of primary and metastatic UM. Compared to chemotherapy or electroporation, ECT caused a reduction in tumor size and viability of tumor cells. Spheroids treated by ECT (with bleomycin in lower concentration $2.5 \mu \mathrm{g} / \mathrm{mL}$ than peak plasma) lose sphericity and cells around. Peripherally located cells detach from the main spheroid body. ECT treatment changes the spheroid shape, alters the inner area core with necrotic cells, and the outer area consists of proliferative cells $[115,116]$. Bleomycin combined with electroporation reduced the viability of conjunctival cell lines (CRMM1, CRMM2). Application electroporation highly enhances the activity of bleomycin chemotherapy in vitro [117]. In the in vivo model, apoptosis and necrosis areas in the peripheral graft region were observed after intraarterial infusion in the tumor's proximity. The intratumoral treatment gives large necrosis in the center of tumor mass [116].

Simulation studies on the 3D mathematical model of the eye show that nonthermal irreversible electroporation can be safely applied to treat intraocular tumors [118]. Ex vivo experiments demonstrated ablation of uveal melanoma tumors, but tumor conductivity increased during treatment [119]. Optimization of pulse parameters and electrode configuration are important factors before planning treatment. Animal and human studies are still needed to develop ECT for clinical use [118].

\section{Theranostics}

Theranostics, also known as theragnosis, is a modern technique in personalized medicine incorporating both diagnostic imaging and therapy. Instead of utilizing two different materials for both purposes, theranostics uses a single probe combing two features into one platform (fig. 6) [120]. This dual property allows recognition of the specific disease, understanding the cellular phenotype, and provides immediately targeted treatment to monitor and observe its efficacy $[121,122]$. Therefore, most directed targets in oncology of this method include antigens and receptors expressed specifically by certain tumor cells (e.g., insulin-like growth factor 1 receptor - IGF1R, epidermal growth factor receptor EGFR, human epidermal growth factor receptor 2 - HER2), elements of the tumor 
microenvironment as well as altered cell metabolism or hypoxia, and extracellular acidosis caused by abnormal vasculature. Such cancer-specific targeting results in selective action of anticancer substances and limiting or even eliminating systemic side effects by reducing its harmful effects on healthy tissues [123].

\section{THERANOSTICS NANOPARTICLE}

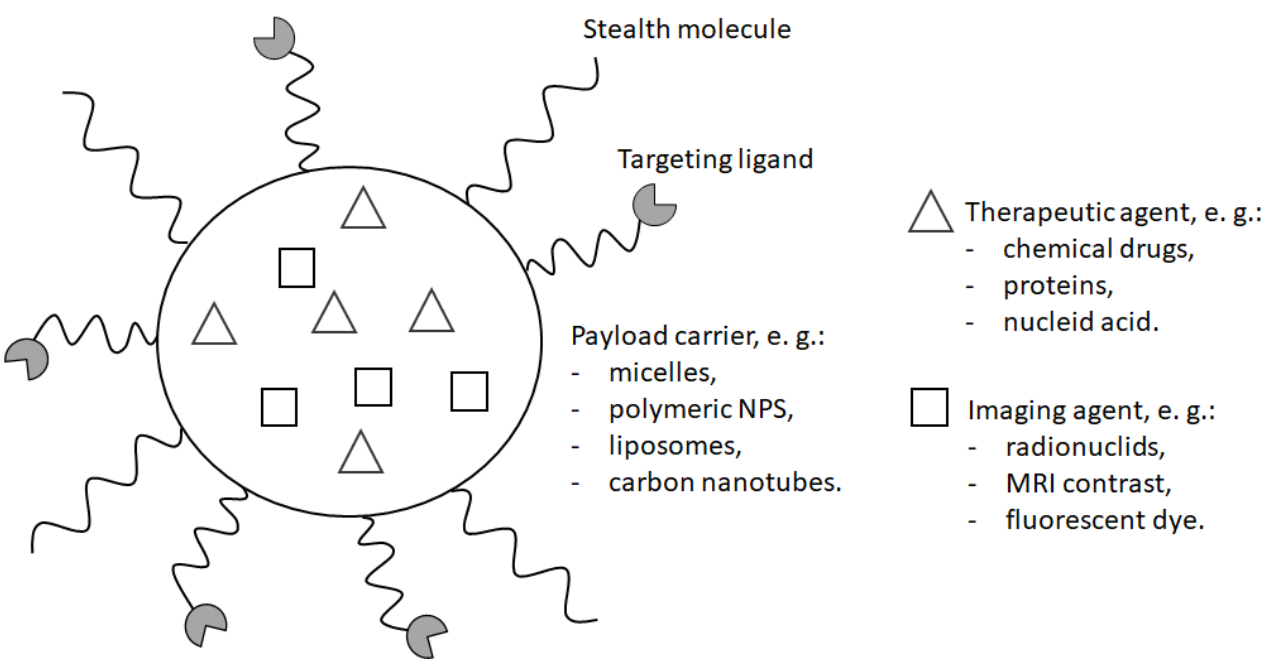

Figure 6. An idea of a nanoparticle used for theranostics. The particle enables imaging, cancertargeting, and therapeutic effect.

Nuclear oncology is one of the main fields which integrated theranostics into clinical practice. Radiopharmaceuticals with $\gamma$-emitting or positron-emitting radionuclides can be easily visualized by positron emission tomography (using emitters such as fluorine-18 or gallium-68), or single-photon emission computed tomography (with the use of emitters such as technetium-99m). When labeled with $\beta$-emitting radionuclides (e.g., lutetium177), they can be utilized as a treatment modality [121,124].

One of the most remarkable achievements of the modern theranostic radionuclide approach was accomplished with the NETTER-1 study [125]. After many years of clinical development, 177-lutetium-DOTA-octreotate for peptide receptor radionuclide therapy (PRRT) of gastroenteropancreatic neuroendocrine tumors (NETs) achieve overall approval. A landmark study involving patients with advanced somatostatin-receptor positive mid-gut NETs was published in 2017. It led to the elevation of PRRT to level $1 \mathrm{~b}$ evidence and FDA approval 177-lutetium-DOTA-octreotate PRRT of gastroenteropancreaticNETs $[126,127]$. Additionally, currently, a new somatostatin-receptor antagonist (the pair 68-gallium-JR11 and 177-lutetium-DOTA-JR11) is tested in patients with not only gastroenteropancreatic NETs but also other cancers, including bronchial carcinoid or phaeochromocytoma (NCT02592707) [126]. Current receptor ligands might be labeled with new radionuclides, e.g., 47-scandium, 161-terbium, 213-bismuth, as evaluated in preclinical trials [127].

Theranostics is a field that heavily gains from the fast development of nanomedicine. Nanoparticles (NPs) offer multifunctionality as they can integrate a few imaging or therapeutic agents and enhance circulation time in the blood. Additionally, by controlling the size and shape of NPs, different demands of biological systems can be met $[128,129]$. Theranostics NPs are engineered in several ways, e.g., by encapsulating therapeutic and imaging agents in platforms such as micelles and polymeric NPs, or by loading therapeutic agents into existing imaging NPs such as gold nanocages and iron oxide NPs, or quantum dots. Theranostics NPs surface is also modified with specific targeting ligands and 
polyethylene glycol to allow active tumor targeting and improve the blood circulation half-life [130]. However, many limitations still exist, including costs and toxicity (e.g., impairment of mitochondrial function, DNA damage) that must be studied and evaluated before introducing theranostics NPs in everyday clinical practice [120,131].

One of the first introduced theranostics NP was Herceptin ${ }^{\circledR}$, developed to treat metastatic breast cancer with HER-2 overexpression [120]. Since then, a lot of new developments have arrived. NPs with anticancerous drugs (e.g., Doxorubicin or Paclitaxel) were combined with imaging agents for simultaneous imaging and targeted chemotherapy. Kim et al. [132] introduced chitosan-based NPs labeled with Cy5.5 (fluorescent dye) for imaging purposes and loaded them with an anticancer drug - paclitaxel. The compound exhibited high accumulation in tumor tissues and resulted in high therapeutic efficacy. Other examples include EGFR targeted liposomes loaded with DNA bio-dots and a combination of anticancer drugs cetuximab and etoposide in treating advanced nonsmall cell lung carcinoma [133].

Additionally, in the treatment of glioblastoma, circulating tumor DNA is being evaluated as a theranostic marker (NCT03115138). The theranostic concept is hope for cancer management. New compounds and materials with appropriate modification and use of long-known anticancer substances allow for selective cancer management.

Although no theranostic NPs have been developed specifically for uveal melanoma, some NPs have already found use in ophthalmology. With limitations from conventional therapies during drug delivery to the eye, nanotechnology-based drugs delivery allows better uptake across ocular barriers, sustained drug release, and tissue targeting. For example, Restasis ${ }^{\oplus}$ was developed as a nanoemulsion with cyclosporin A to treat chronic dry eye. At the same time, intravitreal injection withMacugen ${ }^{\circledR}$, an anti-vascular endothelial growth factor, was approved for age-related macular degeneration treatment $[134,135]$. With increased bioavailability and drug targeting, theranostic NPs for use in imaging and treating uveal melanoma could be an attractive modality, especially in patients with earlystage disease, to reduce side effects and spare healthy tissues of the eye.

\section{Conclusions}

Uveal melanoma is the most common intraocular malignancy and arises from melanocytes in the choroid, ciliary body, or iris. UM's signs and symptoms are non-specific and include high intraocular pressure, myodesopsia, photopsia, or finally, loss of vision. The management of localized UM is either globe-preserving therapy or enucleation. Globe-preserving therapies may be surgical, radiation therapy, or laser therapy.

Ocular pharmacology is extremely unique. The drug administration routes and therapeutic challenges vary depending on the eye segment. The anterior segment of the eye includes the cornea, iris, ciliary body, and lens. Topical application is the most common form of pharmacotherapy in this segment.

Radiotherapy is the mainstay of therapy for most patients with localized uveal melanoma. Due to the predicted radioresistance of melanoma cells, high fraction doses are required to achieve satisfactory response and local control. Another RT technique used in the treatment of uveal melanomas is charged-particle radiotherapy. It includes protons, carbon ions, and helium ions. Unfortunately, the availability of CRT, especially ion therapy, remains poor due to the high cost of equipment and treatment.

Photodynamic therapy is a commonly used modality in treating various kinds of eye diseases, including uveal melanoma. Photodynamic therapy action is based on the selective destruction of cancer cells or pathological vessels. The PDT mechanism uses light (laser energy) to activate photosensitizers, generating reactive oxygen species that kill cells. Additionally, it should be non-toxic to normal cells. Currently, in clinical settings, verteporfin is used as a photosensitizer. Although it is approved for the treatment of AMD and CNV, studies have shown that verteporfin mediated PDT is an effective, safe, and well-tolerated method of uveal melanomas treatment. 
High-Intensity Focused Ultrasound has been proposed to treat solid tumors located in various organs. The HIFU technique is a promising and dynamically developing technology of thermal destruction of solid tumors located deep under the skin. The principle of operation of this technique is based on very quick heating of a small local volume inside the treated tumor to a temperature above $56^{\circ} \mathrm{C}$, leading to its coagulation necrosis due to the absorption of the energy of ultrasonic waves concentrated in the focal volume of the beam, as well as due to the cavitation that destroys the tissue mechanically. The critical condition is to raise the temperature very quickly to a cytotoxic level so that the tissue vascular system does not significantly influence the volume of damaged tissue.

Sonodynamic therapy was developed from photodynamic therapy. A similar effect of both therapies is to induce the reactive oxygen species and kill cancer cells, but the excitation mechanisms of SDT and PDT are different. SDT is less invasive than PDT. U1trasounds may penetrate deep into tissues, opposite photodynamic, limiting permeability light to deep tumor tissues.

Electroporation applied in vivo delivers drugs or genetic material from the intercellular space to the cells by temporarily permeabilizing cell membranes using a short-term high voltage electrical pulse. The first stage is the introduction of a substance (drug, DNA) into the intercellular space. This approach can be achieved through intravenous or local administration (e.g., intratumorally, directly into cancerous tissue). Intravenous administration is less effective in tumors because of the usually increased pressure in the intercellular space. Data from the in vitro studies indicate that electroporation-assisted administration of chemotherapeutic agents in ocular neoplasms may be a promising new therapy.

Iontophoresis is a non-invasive technique in which using low-intensity electric current allows to increase the biodistribution of ionized drug molecules in the eyeball tissues, particularly in the cornea and sclera. Transcorneal iontophoresis has been shown to increase the local concentration of antibacterial and antifungal drugs, steroids, DNA, and RNA molecules.

Theranostics is a modern technique in personalized medicine incorporating both diagnostic imaging and therapy. Instead of utilizing two different materials for both purposes, theranostics uses a single probe combing two features into one platform. Cancerspecific targeting results in selective action of anticancer substances and limiting or even eliminating systemic side effects by reducing its harmful effects on healthy tissues. Although no theranostic markers have been developed specifically for uveal melanoma, some NPs have already found use in ophthalmology. With limitations from conventional therapies during drug delivery to the eye, nanotechnology-based drugs delivery allows better uptake across ocular barriers, sustained drug release, and tissue targeting.

Definitely, uveal melanoma presents an unmet clinical need. More novel eye-preserving therapeutic approaches for the localized disease are desperately needed. Both preclinical research and clinical trials would help to develop these therapies.

Author Contributions: M.F., A.M.C., and K.B., conceptualization; K.J.S., M.F., M.J.S., T.K., P.M., M.D.T., M.S., K.B, original draft preparation; M.F., A.M.C., and K.B., writing - review and editing; M.S, visualization; M.F., A.M.C. and K.B., supervision; M.F., funding acquisition. All authors have read and agreed to the published version of the manuscript.

Funding: This study was supported by Polish National Centre for Research and Development (grant no. LIDER/39/0215/L-10/18/NCBR/2019).

Institutional Review Board Statement: Not applicable.

Informed Consent Statement: Not applicable.

Acknowledgments: We would like to thank Mrs. Monika Janisz for her excellent support in preparing the figures.

Conflicts of Interest: The authors declare no conflict of interest. The funder had no role in the design of the study; in the collection, analyses, or interpretation of data; in the writing of the manuscript, or in the decision to publish the results. 


\section{References}

1. Kaliki, S.; Shields, C.L. Uveal melanoma: relatively rare but deadly cancer. Eye (Lond) 2017, 31, 241-257, doi:10.1038/eye.2016.275.

2. Fallico, M.; Raciti, G.; Longo, A.; Reibaldi, M.; Bonfiglio, V.; Russo, A.; Caltabiano, R.; Gattuso, G.; Falzone, L.; Avitabile, T. Current molecular and clinical insights into uveal melanoma (Review). Int J Oncol 2021, 58, doi:10.3892/ijo.2021.5190.

3. Krantz, B.A.; Dave, N.; Komatsubara, K.M.; Marr, B.P.; Carvajal, R.D. Uveal melanoma: epidemiology, etiology, and treatment of primary disease. Clin Ophthalmol 2017, 11, 279-289, doi:10.2147/OPTH.S89591.

4. Shields, C.L.; Kaliki, S.; Furuta, M.; Mashayekhi, A.; Shields, J.A. Clinical spectrum and prognosis of uveal melanoma based on age at presentation in 8,033 cases. Retina 2012, 32, 1363-1372, doi:10.1097/IAE.0b013e31824d09a8.

5. Fallico, M.; Raciti, G.; Longo, A.; Reibaldi, M.; Bonfiglio, V.; Russo, A.; Caltabiano, R.; Gattuso, G.; Falzone, L.; Avitabile, T. Current molecular and clinical insights into uveal melanoma (Review). Int J Oncol 2021, 58, 10, doi:10.3892/ijo.2021.5190.

6. van Poppelen, N.M.; de Bruyn, D.P.; Bicer, T.; Verdijk, R.; Naus, N.; Mensink, H.; Paridaens, D.; de Klein, A.; Brosens, E.; Kili, E. Genetics of Ocular Melanoma: Insights into Genetics, Inheritance and Testing. Int J Mol Sci 2020, 22, doi:10.3390/ijms22010336.

7. Chang, M.Y.; McCannel, T.A. Local treatment failure after globe-conserving therapy for choroidal melanoma. $B r J$ Ophthalmol 2013, 97, 804-811, doi:10.1136/bjophthalmol-2012-302490.

8. Chen, H. Recent developments in ocular drug delivery. Journal of drug targeting 2015, 23, 597-604, doi:10.3109/1061186x.2015.1052073.

9. Awwad, S.; Mohamed Ahmed, A.H.A.; Sharma, G.; Heng, J.S.; Khaw, P.T.; Brocchini, S.; Lockwood, A. Principles of pharmacology in the eye. 2017, 174, 4205-4223, doi:https://doi.org/10.1111/bph.14024.

10. Urtti, A. Challenges and obstacles of ocular pharmacokinetics and drug delivery. Advanced drug delivery reviews 2006, 58, 1131-1135, doi:10.1016/j.addr.2006.07.027.

11. Geroski, D.H.; Edelhauser, H.F. Drug delivery for posterior segment eye disease. Investigative ophthalmology $\mathcal{E}$ visual science 2000, 41, 961-964.

12. Kompella, U.B.; Kadam, R.S.; Lee, V.H. Recent advances in ophthalmic drug delivery. Therapeutic delivery 2010, 1, 435-456, doi:10.4155/tde.10.40.

13. Occhiutto, M.L.; Freitas, F.R.; Maranhao, R.C.; Costa, V.P. Breakdown of the blood-ocular barrier as a strategy for the systemic use of nanosystems. Pharmaceutics 2012, 4, 252-275, doi:10.3390/pharmaceutics4020252.

14. Tombran-Tink, J.; Barnstable, C. Ocular Transporters In Ophthalmic Diseases And Drug Delivery: Ophthalmology Research; 2008; 10.1007/978-1-59745-375-2.

15. Thrimawithana, T.R.; Young, S.; Bunt, C.R.; Green, C.; Alany, R.G. Drug delivery to the posterior segment of the eye. Drug discovery today 2011, 16, 270-277, doi:10.1016/j.drudis.2010.12.004.

16. van den Aardweg, G.J.; Naus, N.C.; Verhoeven, A.C.; de Klein, A.; Luyten, G.P. Cellular radiosensitivity of primary and metastatic human uveal melanoma cell lines. Invest Ophthalmol Vis Sci 2002, 43, 2561-2565.

17. Yang, J.; Manson, D.K.; Marr, B.P.; Carvajal, R.D. Treatment of uveal melanoma: where are we now? Ther Adv Med Oncol 2018, 10, 1758834018757175-1758834018757175, doi:10.1177/1758834018757175.

18. Ciernik, I.F.; Wösle, M.; Krause, L.; Krayenbuehl, J. Optimizing radiosurgery with photons for ocular melanoma. Physics and Imaging in Radiation Oncology 2018, 6, 83-88, doi:https://doi.org/10.1016/j.phro.2018.06.001.

19. Vrabec, T.R.; Augsburger, J.J.; Gamel, J.W.; Brady, L.W.; Hernandez, C.; Woodleigh, R. Impact of local tumor relapse on patient survival after cobalt 60 plaque radiotherapy. Ophthalmology 1991, 98, 984-988, doi:10.1016/s0161-6420(91)32193-6. 
20. Harbour, J.W.; Char, D.H.; Kroll, S.; Quivey, J.M.; Castro, J. Metastatic risk for distinct patterns of postirradiation local recurrence of posterior uveal melanoma. Ophthalmology 1997, 104, 1785-1792; discussion 1792-1783, doi:10.1016/s01616420(97)30025-6.

21. Chang, M.Y.; McCannel, T.A. Local treatment failure after globe-conserving therapy for choroidal melanoma. 2013, 97, 804811, doi:10.1136/bjophthalmol-2012-302490 \%J British Journal of Ophthalmology.

Bell, D.J.; Wilson, M.W. Choroidal Melanoma: Natural History and Management Options. 2004, 11, 296-303, doi:10.1177/107327480401100503.

23. Group, C.O.M.S. The COMS randomized trial of iodine 125 brachytherapy for choroidal melanoma: V. Twelve-year mortality rates and prognostic factors: COMS report No. 28. Archives of ophthalmology (Chicago, Ill. : 1960) 2006, 124, 16841693, doi:10.1001/archopht.124.12.1684.

24. Filì, M.; Trocme, E.; Bergman, L.; See, T.R.O.; André, H.; Bartuma, K.; Girnita, L.; All-Eriksson, C.; Seregard, S.; Stålhammar, G. Ruthenium-106 versus iodine-125 plaque brachytherapy of 571 choroidal melanomas with a thickness of $\geqslant 5.5 \mathrm{~mm}$. 2020, 104, 26-32, doi:10.1136/bjophthalmol-2018-313419 \%J British Journal of Ophthalmology.

25. Lommatzsch, P.K.; Werschnik, C.; Schuster, E. Long-term follow-up of Ru-106/Rh-106 brachytherapy for posterior uveal melanoma. Graefe's archive for clinical and experimental ophthalmology = Albrecht von Graefes Archiv fur klinische und experimentelle Ophthalmologie 2000, 238, 129-137, doi:10.1007/p100007880.

26. Marinkovic, M.; Horeweg, N.; Laman, M.S.; Bleeker, J.C.; Ketelaars, M.; Peters, F.P.; Luyten, G.P.M.; Creutzberg, C.L. Ruthenium-106 brachytherapy for iris and iridociliary melanomas. Br J Ophthalmol 2018, 102, 1154-1159, doi:10.1136/bjophthalmol-2017-310688.

27. Ghassemi, F.; Sheibani, S.; Arjmand, M.; Poorbaygi, H.; Kouhestani, E.; Sabour, S.; Samiei, F.; Beiki-Ardakani, A.; Jabarvand, M.; Sadeghi Tari, A. Comparison of Iodide-125 and Ruthenium-106 Brachytherapy in the Treatment of Choroidal Melanomas. Clinical ophthalmology (Auckland, N.Z.) 2020, 14, 339-346, doi:10.2147/OPTH.S235265.

28. Naseripour, M.; Jaberi, R.; Sedaghat, A.; Azma, Z.; Nojomi, M.; Falavarjani, K.G.; Nazari, H. Ruthenium-106 brachytherapy for thick uveal melanoma: reappraisal of apex and base dose radiation and dose rate. J Contemp Brachytherapy 2016, 8, 66-73, doi:10.5114/jcb.2016.57818.

29. Badiyan, S.N.; Rao, R.C.; Apicelli, A.J.; Acharya, S.; Verma, V.; Garsa, A.A.; DeWees, T.; Speirs, C.K.; Garcia-Ramirez, J.; Esthappan, J., et al. Outcomes of iodine-125 plaque brachytherapy for uveal melanoma with intraoperative ultrasonography and supplemental transpupillary thermotherapy. International journal of radiation oncology, biology, physics 2014, 88, 801-805, doi:10.1016/j.ijrobp.2013.12.014.

30. Tabandeh, H.; Chaudhry, N.A.; Murray, T.G.; Ehlies, F.; Hughes, R.; Scott, I.U.; Markoe, A.M. Intraoperative echographic localization of iodine-125 episcleral plaque for brachytherapy of choroidal melanoma. American journal of ophthalmology 2000, 129, 199-204, doi:10.1016/s0002-9394(99)00315-3.

31. Almony, A.; Breit, S.; Zhao, H.; Garcia-Ramirez, J.; Mansur, D.B.; Harbour, J.W. Tilting of radioactive plaques after initial accurate placement for treatment of uveal melanoma. Archives of ophthalmology (Chicago, Ill. : 1960) 2008, 126, 65-70, doi:10.1001/archophthalmol.2007.9.

32. Force, A.B.S.-O.O.T. The American Brachytherapy Society consensus guidelines for plaque brachytherapy of uveal melanoma and retinoblastoma. Brachytherapy 2014, 13, 1-14, doi:10.1016/j.brachy.2013.11.008.

33. Dunavoelgyi, R.; Dieckmann, K.; Gleiss, A.; Sacu, S.; Kircher, K.; Georgopoulos, M.; Georg, D.; Zehetmayer, M.; Poetter, R. Radiogenic side effects after hypofractionated stereotactic photon radiotherapy of choroidal melanoma in 212 patients treated between 1997 and 2007. International journal of radiation oncology, biology, physics 2012, 83, 121-128, doi:10.1016/j.ijrobp.2011.06.1957.

34. Saunders, W.M.; Char, D.H.; Quivey, J.M.; Castro, J.R.; Chen, G.T.; Collier, J.M.; Cartigny, A.; Blakely, E.A.; Lyman, J.T.; Zink, S.R., et al. Precision, high dose radiotherapy: helium ion treatment of uveal melanoma. International journal of radiation oncology, biology, physics 1985, 11, 227-233, doi:10.1016/0360-3016(85)90143-9. 
35. Lane, A.M.; Kim, I.K.; Gragoudas, E.S. Long-term Risk of Melanoma-Related Mortality for Patients With Uveal Melanoma Treated With Proton Beam Therapy. JAMA ophthalmology 2015, 133, 792-796, doi:10.1001/jamaophthalmol.2015.0887.

36. Tsuji, H.; Ishikawa, H.; Yanagi, T.; Hirasawa, N.; Kamada, T.; Mizoe, J.E.; Kanai, T.; Tsujii, H.; Ohnishi, Y. Carbon-ion radiotherapy for locally advanced or unfavorably located choroidal melanoma: a Phase I/II dose-escalation study. International journal of radiation oncology, biology, physics 2007, 67, 857-862, doi:10.1016/j.ijrobp.2006.09.022.

Caujolle, J.P.; Mammar, H.; Chamorey, E.; Pinon, F.; Herault, J.; Gastaud, P. Proton beam radiotherapy for uveal melanomas at nice teaching hospital: 16 years' experience. International journal of radiation oncology, biology, physics 2010, 78, 98-103, doi:10.1016/j.ijrobp.2009.07.1688.

38. Dendale, R.; Lumbroso-Le Rouic, L.; Noel, G.; Feuvret, L.; Levy, C.; Delacroix, S.; Meyer, A.; Nauraye, C.; Mazal, A.; Mammar, H., et al. Proton beam radiotherapy for uveal melanoma: Results of Curie Institut-Orsay Proton Therapy Center (ICPO). International Journal of Radiation Oncology*Biology*Physics 2006, 65, 780-787, doi:https://doi.org/10.1016/j.ijrobp.2006.01.020.

39. Egger, E.; Schalenbourg, A.; Zografos, L.; Bercher, L.; Boehringer, T.; Chamot, L.; Goitein, G. Maximizing local tumor control and survival after proton beam radiotherapy of uveal melanoma. International Journal of Radiation Oncology*Biology*Physics 2001, 51, 138-147, doi:https://doi.org/10.1016/S0360-3016(01)01560-7.

40. Peddada, K.V.; Sangani, R.; Menon, H.; Verma, V. Complications and adverse events of plaque brachytherapy for ocular melanoma. J Contemp Brachytherapy 2019, 11, 392-397, doi:10.5114/jcb.2019.87407.

41. Giuliari, G.P.; Sadaka, A.; Hinkle, D.M.; Simpson, E.R. Current treatments for radiation retinopathy. Acta oncologica (Stockholm, Sweden) 2011, 50, 6-13, doi:10.3109/0284186x.2010.500299.

42. Mills, M.D.; Harbour, J.W. Lipid exudation following plaque radiotherapy for posterior uveal melanoma. American journal of ophthalmology 2006, 141, 594-595, doi:10.1016/j.ajo.2005.10.015.

43. Pagliara, M.M.; Tagliaferri, L.; Azario, L.; Lenkowicz, J.; Lanza, A.; Autorino, R.; Caputo, C.G.; Gambacorta, M.A.; Valentini, V.; Blasi, M.A. Ruthenium brachytherapy for uveal melanomas: Factors affecting the development of radiation complications. Brachytherapy 2018, 17, 432-438, doi:10.1016/j.brachy.2017.11.004.

44. Miguel, D.; de Frutos-Baraja, J.M.; López-Lara, F.; Antonia Saornil, M.; García-Alvarez, C.; Alonso, P.; Diezhandino, P. Visual outcome after posterior uveal melanoma episcleral brachytherapy including radiobiological doses. J Contemp Brachytherapy 2018, 10, 123-131, doi:10.5114/jcb.2018.75597.

45. McCannel, T.A. Post-brachytherapy tumor endoresection for treatment of toxic maculopathy in choroidal melanoma. Eye (Lond) 2013, 27, 984-988, doi:10.1038/eye.2013.115.

46. Tagliaferri, L.; Pagliara, M.M.; Masciocchi, C.; Scupola, A.; Azario, L.; Grimaldi, G.; Autorino, R.; Gambacorta, M.A.; Laricchiuta, A.; Boldrini, L., et al. Nomogram for predicting radiation maculopathy in patients treated with Ruthenium-106 plaque brachytherapy for uveal melanoma. J Contemp Brachytherapy 2017, 9, 540-547, doi:10.5114/jcb.2017.71795.

47. Finger, P.T.; Chin, K.J.; Semenova, E.A. Intravitreal anti-VEGF therapy for macular radiation retinopathy: a 10-year study. European journal of ophthalmology 2016, 26, 60-66, doi:10.5301/ejo.5000670.

48. Mishra, K.K.; Daftari, I.K.; Weinberg, V.; Cole, T.; Quivey, J.M.; Castro, J.R.; Phillips, T.L.; Char, D.H. Risk factors for neovascular glaucoma after proton beam therapy of uveal melanoma: a detailed analysis of tumor and dose-volume parameters. International journal of radiation oncology, biology, physics 2013, 87, 330-336, doi:10.1016/j.ijrobp.2013.05.051.

49. Shields, C.L.; Shields, J.A.; Karlsson, U.; Markoe, A.M.; Brady, L.W. Reasons for enucleation after plaque radiotherapy for posterior uveal melanoma. Clinical findings. Ophthalmology 1989, 96, 919-923; discussion 924, doi:10.1016/s01616420(89)32806-5.

50. Piirtola, A.; Puska, P.; Kivelä, T. Red laser cyclophotocoagulation in the treatment of secondary glaucoma in eyes with uveal melanoma. Journal of glaucoma 2014, 23, 50-55, doi:10.1097/IJG.0b013e31825c0fb7.

51. Nagendran, S.T.; Finger, P.T. Anti-VEGF intravitreal bevacizumab for radiation-associated neovascular glaucoma. Ophthalmic surgery, lasers $\mathcal{E}$ imaging retina 2015, 46, 201-207, doi:10.3928/23258160-20150213-08. 
52. Newman, D.K. Photodynamic therapy: current role in the treatment of chorioretinal conditions. Eye (London, England) 2016, 30, 202-210, doi:10.1038/eye.2015.251.

53. Blasi, M.A.; Pagliara, M.M.; Lanza, A.; Sammarco, M.G.; Caputo, C.G.; Grimaldi, G.; Scupola, A. Photodynamic Therapy in Ocular Oncology. 2018, 6, 17.

54. Leviskas, B.; Valyi-Nagy, T.; Munirathinam, G.; Bork, M.; Valyi-Nagy, K.; Skwor, T. Metalloporphyrin Pd(T4) Exhibits Oncolytic Activity and Cumulative Effects with 5-ALA Photodynamic Treatment against C918 Cells. 2020, $21,669$.

55. Kawczyk-Krupka, A.; Bugaj, A.M.; Latos, W.; Zaremba, K.; Sieroń, A. Photodynamic therapy in treatment of cutaneous and choroidal melanoma. Photodiagnosis and photodynamic therapy 2013, 10, 503-509, doi:10.1016/j.pdpdt.2013.05.006.

56. Juan, L.; Diandian, W.; Jianfeng, W.; Ning, L.; Yuchen, F.; Na, L.; Sijie, Z.; Kun, L.; Fengyuan, S. Efficient Anticancer Effect on Choroidal Melanoma Cells Induced by Tanshinone IIA Photosensitization. Photochemistry and Photobiology 2021, 97, 841850, doi:https://doi.org/10.1111/php.13399.

Ebbini, E.S.; ter Haar, G. Ultrasound-guided therapeutic focused ultrasound: current status and future directions. International journal of hyperthermia : the official journal of European Society for Hyperthermic Oncology, North American Hyperthermia Group 2015, 31, 77-89, doi:10.3109/02656736.2014.995238.

58. Fabian, I.D.; Stacey, A.W.; Papastefanou, V.; Al Harby, L.; Arora, A.K.; Sagoo, M.S.; Cohen, V.M. Primary photodynamic therapy with verteporfin for small pigmented posterior pole choroidal melanoma. Eye (London, England) 2017, 31, 519-528, doi:10.1038/eye.2017.22.

59. Turkoglu, E.B.; Pointdujour-Lim, R.; Mashayekhi, A.; Shields, C.L. PHOTODYNAMIC THERAPY AS PRIMARY TREATMENT FOR SMALL CHOROIDAL MELANOMA. Retina 2019, 39, 1319-1325, doi:10.1097/iae.0000000000002169.

60. Rundle, P. Treatment of posterior uveal melanoma with multi-dose photodynamic therapy. The British journal of ophthalmology 2014, 98, 494-497, doi:10.1136/bjophthalmol-2013-304432.

61. Rundle, P. Treatment of posterior uveal melanoma with multi-dose photodynamic therapy. British Journal of Ophthalmology 2014, 98, 494, doi:10.1136/bjophthalmol-2013-304432.

62. Rundle, P. Photodynamic Therapy for Eye Cancer. Biomedicines 2017, 5, doi:10.3390/biomedicines5040069.

63. Roelofs, K.A.; Fabian, I.D.; Arora, A.K.; Cohen, V.M.L.; Sagoo, M.S. Long-term Outcomes of Small Pigmented Choroidal Melanoma Treated with Primary Photodynamic Therapy. Ophthalmology. Retina 2021, 5, 468-478, doi:10.1016/j.oret.2020.08.019.

64. Yordi, S.; Soto, H.; Bowen, R.C.; Singh, A.D. Photodynamic therapy for choroidal melanoma: What is the response rate? Survey of Ophthalmology 2021, 66, 552-559, doi:10.1016/j.survophthal.2020.09.006.

65. Chaussy, C.G.; Thüroff, S. High-Intensity Focused Ultrasound for the Treatment of Prostate Cancer: A Review. Journal of endourology 2017, 31, S30-s37, doi:10.1089/end.2016.0548.

66. Illing, R.O.; Kennedy, J.E.; Wu, F.; ter Haar, G.R.; Protheroe, A.S.; Friend, P.J.; Gleeson, F.V.; Cranston, D.W.; Phillips, R.R.; Middleton, M.R. The safety and feasibility of extracorporeal high-intensity focused ultrasound (HIFU) for the treatment of liver and kidney tumours in a Western population. British journal of cancer 2005, 93, 890-895, doi:10.1038/sj.bjc.6602803.

67. Ji, Y.; Zhang, Y.; Zhu, J.; Zhu, L.; Zhu, Y.; Hu, K.; Zhao, H. High intensity focused ultrasound (HIFU) for primary hepatocellular carcinoma: a single center experience. Int J Clin Exp Med 2017, 10, 15432-15438.

68. Kim, S.H.; Jung, S.E.; Kim, H.L.; Hahn, S.T.; Park, G.S.; Park, W.C. The potential role of dynamic MRI in assessing the effectiveness of high-intensity focused ultrasound ablation of breast cancer. International journal of hyperthermia: the official journal of European Society for Hyperthermic Oncology, North American Hyperthermia Group 2010, 26, 594-603, doi:10.3109/02656736.2010.481275.

69. Wu, F.; Wang, Z.B.; Cao, Y.D.; Chen, W.Z.; Bai, J.; Zou, J.Z.; Zhu, H. A randomised clinical trial of high-intensity focused ultrasound ablation for the treatment of patients with localised breast cancer. British journal of cancer 2003, 89, 2227-2233, doi:10.1038/sj.bjc.6601411. 
70. Wu, F.; Wang, Z.B.; Zhu, H.; Chen, W.Z.; Zou, J.Z.; Bai, J.; Li, K.Q.; Jin, C.B.; Xie, F.L.; Su, H.B. Extracorporeal high intensity focused ultrasound treatment for patients with breast cancer. Breast cancer research and treatment 2005, 92, 51-60, doi:10.1007/s10549-004-5778-7.

71. Fornage, B.D.; Hwang, R.F. Current status of imaging-guided percutaneous ablation of breast cancer. AJR. American journal of roentgenology 2014, 203, 442-448, doi:10.2214/ajr.13.11600.

Schmitz, A.C.; Gianfelice, D.; Daniel, B.L.; Mali, W.P.; van den Bosch, M.A. Image-guided focused ultrasound ablation of breast cancer: current status, challenges, and future directions. European radiology 2008, 18, 1431-1441, doi:10.1007/s00330008-0906-0.

73. Bohlmann, M.K.; Hoellen, F.; Hunold, P.; David, M. High-Intensity Focused Ultrasound Ablation of Uterine Fibroids Potential Impact on Fertility and Pregnancy Outcome. Geburtshilfe und Frauenheilkunde 2014, 74, 139-145, doi:10.1055/s-00331360311.

74. ter Haar, G. Therapeutic applications of ultrasound. Progress in biophysics and molecular biology 2007, 93, 111-129, doi:10.1016/j.pbiomolbio.2006.07.005.

75. Zhou, Y.F. High intensity focused ultrasound in clinical tumor ablation. World journal of clinical oncology 2011, 2, 8-27, doi:10.5306/wjco.v2.i1.8.

ter Haar, G. Ultrasound focal beam surgery. Ultrasound in medicine $\mathcal{E}$ biology 1995, 21, 1089-1100, doi:10.1016/03015629(95)02010-1.

Haar, G.T.; Coussios, C. High intensity focused ultrasound: physical principles and devices. Int J Hyperthermia 2007, 23, 89104, doi:10.1080/02656730601186138.

78. Alkins, R.D.; Mainprize, T.G. High-Intensity Focused Ultrasound Ablation Therapy of Gliomas. Prog Neurol Surg 2018, 32, 39-47, doi:10.1159/000469678.

Haut, J.; Colliac, J.P.; Falque, L.; Renard, Y. [Indications and results of Sonocare (ultrasound) in the treatment of ocular hypertension. A preliminary study of 395 cases]. Ophtalmologie : organe de la Societe francaise d'ophtalmologie 1990, 4, 138-141.

80. Muratore, R. A History of the Sonocare CSt 100: The First FDa approved HIFU Device.

81. Costley, D.; Mc Ewan, C.; Fowley, C.; McHale, A.P.; Atchison, J.; Nomikou, N.; Callan, J.F. Treating cancer with sonodynamic therapy: a review. International journal of hyperthermia : the official journal of European Society for Hyperthermic Oncology, North American Hyperthermia Group 2015, 31, 107-117, doi:10.3109/02656736.2014.992484.

82. Qian, X.; Zheng, Y.; Chen, Y. Micro/Nanoparticle-Augmented Sonodynamic Therapy (SDT): Breaking the Depth Shallow of Photoactivation. Advanced materials (Deerfield Beach, Fla.) 2016, 28, 8097-8129, doi:10.1002/adma.201602012.

83. Chen, H.; Zhou, X.; Gao, Y.; Zheng, B.; Tang, F.; Huang, J. Recent progress in development of new sonosensitizers for sonodynamic cancer therapy. Drug discovery today 2014, 19, 502-509, doi:10.1016/j.drudis.2014.01.010.

84. Rengeng, L.; Qianyu, Z.; Yuehong, L.; Zhongzhong, P.; Libo, L. Sonodynamic therapy, a treatment developing from photodynamic therapy. Photodiagnosis and photodynamic therapy 2017, 19, 159-166, doi:10.1016/j.pdpdt.2017.06.003.

85. McEwan, C.; Nesbitt, H.; Nicholas, D.; Kavanagh, O.N.; McKenna, K.; Loan, P.; Jack, I.G.; McHale, A.P.; Callan, J.F. Comparing the efficacy of photodynamic and sonodynamic therapy in non-melanoma and melanoma skin cancer. Bioorganic $\mathcal{E}$ medicinal chemistry 2016, 24, 3023-3028, doi:10.1016/j.bmc.2016.05.015.

86. Dai, S.; Xu, C.; Tian, Y.; Cheng, W.; Li, B. In vitro stimulation of calcium overload and apoptosis by sonodynamic therapy combined with hematoporphyrin monomethyl ether in C6 glioma cells. Oncol Lett 2014, 8, 1675-1681, doi:10.3892/ol.2014.2419.

87. Su, X.; Wang, P.; Wang, X.; Cao, B.; Li, L.; Liu, Q. Apoptosis of U937 cells induced by hematoporphyrin monomethyl ethermediated sonodynamic action. Cancer biotherapy E radiopharmaceuticals 2013, 28, 207-217, doi:10.1089/cbr.2012.1190.

88. Su, X.; Li, Y.; Wang, P.; Wang, X.; Liu, Q. Protoporphyrin IX-mediated sonodynamic action induces apoptosis of K562 cells. Ultrasonics 2014, 54, 275-284, doi:10.1016/j.ultras.2013.07.015. 
89. Wang, S.; Hu, Z.; Wang, X.; Gu, C.; Gao, Z.; Cao, W.; Zheng, J. 5-Aminolevulinic acid-mediated sonodynamic therapy reverses macrophage and dendritic cell passivity in murine melanoma xenografts. Ultrasound in medicine $\mathcal{E}$ biology 2014, 40, 2125-2133, doi:10.1016/j.ultrasmedbio.2014.05.007.

90. Yumita, N.; Nishigaki, R.; Umemura, K.; Umemura, S. Hematoporphyrin as a sensitizer of cell-damaging effect of ultrasound. Japanese journal of cancer research : Gann 1989, 80, 219-222, doi:10.1111/j.1349-7006.1989.tb02295.x.

91. Sun, T.; Zhang, Y.S.; Pang, B.; Hyun, D.C.; Yang, M.; Xia, Y. Engineered nanoparticles for drug delivery in cancer therapy. Angewandte Chemie (International ed. in English) 2014, 53, 12320-12364, doi:10.1002/anie.201403036.

92. Pan, X.; Wang, H.; Wang, S.; Sun, X.; Wang, L.; Wang, W.; Shen, H.; Liu, H. Sonodynamic therapy (SDT): a novel strategy for cancer nanotheranostics. Science China. Life sciences 2018, 61, 415-426, doi:10.1007/s11427-017-9262-x.

93. Harada, Y.; Ogawa, K.; Irie, Y.; Endo, H.; Feril, L.B., Jr.; Uemura, T.; Tachibana, K. Ultrasound activation of TiO2 in melanoma tumors. Journal of controlled release : official journal of the Controlled Release Society 2011, 149, 190-195, doi:10.1016/j.jconrel.2010.10.012.

94. Khan-Lim, D.; Berry, M. Still confused about rose bengal? Current eye research 2004, 29, 311-317, doi:10.1080/02713680490516864.

95. Mousavi, H.; Zhang, X.; Gillespie, S.; Wachter, E.; Hersey, P. Rose Bengal induces dual modes of cell death in melanoma cells and has clinical activity against melanoma. Melanoma Research 2006, 16.

96. Srivastav, A.K.; Mujtaba, S.F.; Dwivedi, A.; Amar, S.K.; Goyal, S.; Verma, A.; Kushwaha, H.N.; Chaturvedi, R.K.; Ray, R.S. Photosensitized rose Bengal-induced phototoxicity on human melanoma cell line under natural sunlight exposure. Journal of photochemistry and photobiology. B, Biology 2016, 156, 87-99, doi:10.1016/j.jphotobiol.2015.12.001.

97. Wan, G.Y.; Liu, Y.; Chen, B.W.; Liu, Y.Y.; Wang, Y.S.; Zhang, N. Recent advances of sonodynamic therapy in cancer treatment. Cancer biology \& medicine 2016, 13, 325-338, doi:10.20892/j.issn.2095-3941.2016.0068.

98. Hoogenboom, M.; Eikelenboom, D.; den Brok, M.H.; Heerschap, A.; Fütterer, J.J.; Adema, G.J. Mechanical high-intensity focused ultrasound destruction of soft tissue: working mechanisms and physiologic effects. Ultrasound in medicine $\mathcal{E}$ biology 2015, 41, 1500-1517, doi:10.1016/j.ultrasmedbio.2015.02.006.

99. Shi, J.; Ma, Y.; Zhu, J.; Chen, Y.; Sun, Y.; Yao, Y.; Yang, Z.; Xie, J. A Review on Electroporation-Based Intracellular Delivery. Molecules (Basel, Switzerland) 2018, 23, doi:10.3390/molecules23113044.

100. Sersa, G.; Novakovic, S.; Miklavcic, D. Potentiation of bleomycin antitumor effectiveness by electrotherapy. Cancer letters 1993, 69, 81-84.

101. Esmaeili, N.; Friebe, M. Electrochemotherapy: A Review of Current Status, Alternative IGP Approaches, and Future Perspectives. Journal of healthcare engineering 2019, 2019, 2784516-2784516, doi:10.1155/2019/2784516.

102. Blair-Parks, K.; Weston, B.C.; Dean, D.A. High-level gene transfer to the cornea using electroporation. The Journal of Gene Medicine 2002, 4, 92-100, doi:doi:10.1002/jgm.231.

103. Touchard, E.; Berdugo, M.; Bigey, P.; El Sanharawi, M.; Savoldelli, M.; Naud, M.-C.; Jeanny, J.-C.; Behar-Cohen, F. Suprachoroidal Electrotransfer: A Nonviral Gene Delivery Method to Transfect the Choroid and the Retina Without Detaching the Retina. Molecular Therapy 2012, 20, 1559-1570, doi:https://doi.org/10.1038/mt.2011.304.

104. Fiorentzis, M.; Kalirai, H.; Katopodis, P.; Seitz, B.; Viestenz, A.; Coupland, S.E. Electrochemotherapy with bleomycin and cisplatin enhances cytotoxicity in primary and metastatic uveal melanoma cell lines in vitro. Neoplasma 2018, 65, 210-215, doi:10.4149/neo_2018_170329N227.

105. Eljarrat-Binstock, E.; Pe'er, J.; Domb, A.J. New techniques for drug delivery to the posterior eye segment. Pharmaceutical research 2010, 27, 530-543, doi:10.1007/s11095-009-0042-9.

106. Gower, N.J.D.; Barry, R.J.; Edmunds, M.R.; Titcomb, L.C.; Denniston, A.K. Drug discovery in ophthalmology: past success, present challenges, and future opportunities. BMC ophthalmology 2016, 16, 11-11, doi:10.1186/s12886-016-0188-2.

107. Availabe online: http://www.eyegatepharma.com (accessed on 2019-03-13). 
108. Hayden, B.; Jockovich, M.-E.; Murray, T.G.; Kralinger, M.T.; Voigt, M.; Hernandez, E.; Feuer, W.; Parel, J.-M. Iontophoretic Delivery of Carboplatin in a Murine Model of Retinoblastoma. Investigative Ophthalmology E Visual Science 2006, 47, 37173721, doi:10.1167/iovs.06-0365 \%J Investigative Ophthalmology \& Visual Science.

109. Hayden, B.; Jockovich, M.-E.; Murray, T.; Voigt, M.; Milne, P.; Kralinger, M.; Feuer, W.; Hernandez, E.; Parel, J.-M. Pharmacokinetics of Systemic Versus Focal Carboplatin Chemotherapy in the Rabbit Eye: Possible Implication in the Treatment of Retinoblastoma. Investigative ophthalmology E visual science 2004, 45, 3644-3649, doi:10.1167/iovs.04-0228.

110. Jung, J.H.; Chiang, B.; Grossniklaus, H.E.; Prausnitz, M.R. Ocular drug delivery targeted by iontophoresis in the suprachoroidal space using a microneedle. Journal of controlled release : official journal of the Controlled Release Society 2018, 277, 14-22, doi:10.1016/j.jconrel.2018.03.001.

111. Campana, L.G.; Testori, A.; Curatolo, P.; Quaglino, P.; Mocellin, S.; Framarini, M.; Borgognoni, L.; Ascierto, P.A.; Mozzillo, N.; Guida, M., et al. Treatment efficacy with electrochemotherapy: A multi-institutional prospective observational study on 376 patients with superficial tumors. Eur J Surg Oncol 2016, 42, 1914-1923, doi:10.1016/j.ejso.2016.06.399.

112. Maglietti, F.; Tellado, M.; Olaiz, N.; Michinski, S.; Marshall, G. Minimally Invasive Electrochemotherapy Procedure for Treating Nasal Duct Tumors in Dogs using a Single Needle Electrode. Radiol Oncol 2017, 51, 422-430, doi:10.1515/raon-20170043.

113. De Vry, J.; Martinez-Martinez, P.; Losen, M.; Temel, Y.; Steckler, T.; Steinbusch, H.W.; De Baets, M.H.; Prickaerts, J. In vivo electroporation of the central nervous system: a non-viral approach for targeted gene delivery. Prog Neurobiol 2010, 92, 227244, doi:10.1016/j.pneurobio.2010.10.001.

114. Cadossi, R.; Ronchetti, M.; Cadossi, M. Locally enhanced chemotherapy by electroporation: clinical experiences and perspective of use of electrochemotherapy. Future Oncol 2014, 10, 877-890, doi:10.2217/fon.13.235.

115. Fiorentzis, M.; Katopodis, P.; Kalirai, H.; Seitz, B.; Viestenz, A.; Coupland, S.E. Image Analysis of 3D Conjunctival Melanoma Cell Cultures Following Electrochemotherapy. 2020, 8, 158.

116. Fiorentzis, M.; Viestenz, A.; Siebolts, U.; Seitz, B.; Coupland, S.E.; Heinzelmann, J. The Potential Use of Electrochemotherapy in the Treatment of Uveal Melanoma: In Vitro Results in 3D Tumor Cultures and In Vivo Results in a Chick Embryo Model. Cancers (Basel) 2019, 11, 1344, doi:10.3390/cancers11091344.

117. Fiorentzis, M.; Katopodis, P.; Kalirai, H.; Seitz, B.; Viestenz, A.; Coupland, S.E. Conjunctival melanoma and electrochemotherapy: preliminary results using 2D and 3D cell culture models in vitro. 2019, 97, e632-e640, doi:https://doi.org/10.1111/aos.13993.

118. Mandel, Y.; Rubinsky, B. Treatment of Uveal Melanoma by Nonthermal Irreversible Electroporation: Electrical and Bioheat Finite Element Model of the Human Eye. Journal of Heat Transfer 2012, 134, 111101, doi:10.1115/1.4005203.

119. Mandel, Y.; Frenkel, S.; Laufer, S.; Rubinsky, B.; Belkin, M.; Pe'er, J. Treatment Of Uveal Melanoma By Non-thermal Irreversible Electroporation - Mathematical Model, Animal And Preliminary Ex-vivo Human Experiments. Investigative Ophthalmology \& Visual Science 2011, 52, 3284-3284.

120. Walia, S.; Acharya, A. Theragnosis: Nanoparticles as a Tool for Simultaneous Therapy and Diagnosis. In Nanoscale Materials in Targeted Drug Delivery, Theragnosis and Tissue Regeneration, Yadav, S.K., Ed. Springer Singapore: Singapore, 2016; 10.1007/978-981-10-0818-4_6pp. 127-152.

121. Kelkar, S.S.; Reineke, T.M. Theranostics: Combining Imaging and Therapy. Bioconjugate Chemistry 2011, 22, 1879-1903, doi:10.1021/bc200151q.

122. Jeyamogan, S.; Khan, N.A.; Siddiqui, R. Application and Importance of Theranostics in the Diagnosis and Treatment of Cancer. Archives of medical research 2021, 52, 131-142, doi:10.1016/j.arcmed.2020.10.016.

123. Bhujwalla, Z.M.; Kakkad, S.; Chen, Z.; Jin, J.; Hapuarachchige, S.; Artemov, D.; Penet, M.F. Theranostics and metabolotheranostics for precision medicine in oncology. Journal of magnetic resonance (San Diego, Calif. : 1997) 2018, 291, 141151, doi:10.1016/j.jmr.2018.03.004. 
124. de Jong, M.; Breeman, W.A.; Kwekkeboom, D.J.; Valkema, R.; Krenning, E.P. Tumor imaging and therapy using radiolabeled somatostatin analogues. Accounts of chemical research 2009, 42, 873-880, doi:10.1021/ar800188e.

125. Strosberg, J.; El-Haddad, G.; Wolin, E.; Hendifar, A.; Yao, J.; Chasen, B.; Mittra, E.; Kunz, P.L.; Kulke, M.H.; Jacene, H., et al. Phase 3 Trial of 177Lu-Dotatate for Midgut Neuroendocrine Tumors. 2017, 376, 125-135, doi:10.1056/NEJMoa1607427.

126. Turner, J.H. An introduction to the clinical practice of theranostics in oncology. 2018, 91, 20180440, doi:10.1259/bjr.20180440.

127. Turner, J.H. Recent advances in theranostics and challenges for the future. 2018, 91, 20170893, doi:10.1259/bjr.20170893.

128. Lee, D.E.; Koo, H.; Sun, I.C.; Ryu, J.H.; Kim, K.; Kwon, I.C. Multifunctional nanoparticles for multimodal imaging and theragnosis. Chemical Society reviews 2012, 41, 2656-2672, doi:10.1039/c2cs15261d.

129. Liao, J.; Qi, T.; Chu, B.; Peng, J.; Luo, F.; Qian, Z. Multifunctional nanostructured materials for multimodal cancer imaging and therapy. Journal of nanoscience and nanotechnology 2014, 14, 175-189, doi:10.1166/jnn.2014.9049.

130. Chen, F.; Ehlerding, E.B.; Cai, W. Theranostic nanoparticles. Journal of nuclear medicine : official publication, Society of Nuclear Medicine 2014, 55, 1919-1922, doi:10.2967/jnumed.114.146019.

131. Kang, H.; Mintri, S.; Menon, A.V.; Lee, H.Y.; Choi, H.S.; Kim, J. Pharmacokinetics, pharmacodynamics and toxicology of theranostic nanoparticles. Nanoscale 2015, 7, 18848-18862, doi:10.1039/C5NR05264E.

132. Kim, K.; Kim, J.H.; Park, H.; Kim, Y.S.; Park, K.; Nam, H.; Lee, S.; Park, J.H.; Park, R.W.; Kim, I.S., et al. Tumor-homing multifunctional nanoparticles for cancer theragnosis: Simultaneous diagnosis, drug delivery, and therapeutic monitoring. Journal of controlled release : official journal of the Controlled Release Society 2010, 146, 219-227, doi:10.1016/j.jconrel.2010.04.004.

133. Jha, A.; Viswanadh, M.K.; Burande, A.S.; Mehata, A.K.; Poddar, S.; Yadav, K.; Mahto, S.K.; Parmar, A.S.; Muthu, M.S. DNA biodots based targeted theranostic nanomedicine for the imaging and treatment of non-small cell lung cancer. International journal of biological macromolecules 2020, 150, 413-425, doi:10.1016/j.ijbiomac.2020.02.075.

134. Khiev, D.; Mohamed, Z.A.; Vichare, R.; Paulson, R.; Bhatia, S.; Mohapatra, S.; Lobo, G.P.; Valapala, M.; Kerur, N.; Passaglia, C.L., et al. Emerging Nano-Formulations and Nanomedicines Applications for Ocular Drug Delivery. 2021, 11, 173.

135. Gote, V.; Sikder, S.; Sicotte, J.; Pal, D. Ocular Drug Delivery: Present Innovations and Future Challenges. The Journal of pharmacology and experimental therapeutics 2019, 370, 602-624, doi:10.1124/jpet.119.256933. 